\title{
Bacterial and eukaryotic intact polar lipids point to in situ production as a key source of labile organic matter in hadal surface sediment of the Atacama Trench
}

\author{
Edgart Flores $^{1,2,3}$, Sebastian I. Cantarero ${ }^{4}$, Paula Ruiz-Fernández ${ }^{1,2,3}$, Nadia Dildar ${ }^{4}$, Matthias Zabel ${ }^{5}$, \\ Osvaldo Ulloa $^{2,3}$, and Julio Sepúlveda ${ }^{3,4}$ \\ ${ }^{1}$ Programa de Postgrado en Oceanografía, Departamento de Oceanografía, Facultad de Ciencias Naturales y Oceanográficas, \\ Universidad de Concepción, Concepción, Chile \\ ${ }^{2}$ Departamento de Oceanografía, Universidad de Concepción, Casilla 160-C, Concepción, Chile \\ ${ }^{3}$ Millennium Institute of Oceanography, Universidad de Concepción, Concepción, Chile \\ ${ }^{4}$ Department of Geological Sciences and Institute of Arctic and Alpine Research, \\ University of Colorado Boulder, Boulder, CO 80309, USA \\ ${ }^{5}$ MARUM - Center for Marine Environmental Sciences and Department of Geosciences, \\ University of Bremen, 28334 Bremen, Germany
}

Correspondence: Edgart Flores (edgart.flores@imo-chile.cl) and Julio Sepúlveda (jsepulveda@colorado.edu)

Received: 30 August 2021 - Discussion started: 3 September 2021

Revised: 27 December 2021 - Accepted: 8 January 2022 - Published: 8 March 2022

\begin{abstract}
Elevated organic matter (OM) concentrations are found in hadal surface sediments relative to the surrounding abyssal seabed. However, the origin of this biological material remains elusive. Here, we report on the composition and distribution of cellular membrane intact polar lipids (IPLs) extracted from surface sediments around the deepest points of the Atacama Trench and adjacent bathyal margin to assess and constrain the sources of labile OM in the hadal seabed. Multiscale bootstrap resampling of IPLs' structural diversity and abundance indicates distinct lipid signatures in the sediments of the Atacama Trench that are more closely related to those found in bathyal sediments than to those previously reported for the upper ocean water column in the region. Whereas the overall number of unique IPL structures in hadal sediments contributes a small fraction of the total IPL pool, we also report a high contribution of phospholipids with mono- and di-unsaturated fatty acids that are not associated with photoautotrophic sources and that resemble traits of physiological adaptation to high pressure and low temperature. Our results indicate that IPLs in hadal sediments of the Atacama Trench predominantly derive from in situ microbial production and biomass, whereas the export of the most labile lipid component of the OM pool from the euphotic zone and the overlying oxygen minimum zone is ne-
\end{abstract}

glectable. While other OM sources such as the downslope and/or lateral transport of labile OM cannot be ruled out and remain to be studied, they are likely less important in view of the lability of ester-bond IPLs. Our results contribute to the understanding of the mechanisms that control the delivery of labile OM to this extreme deep-sea ecosystem. Furthermore, they provide insights into some potential physiological adaptation of the in situ microbial community to high pressure and low temperature through lipid remodeling.

\section{Introduction}

The deep ocean has been classically considered a vast "biological desert" (Danovaro et al., 2003) due to the attenuation of organic matter $(\mathrm{OM})$ fluxes with increasing depth (Wakeham et al., 1984; Martin et al., 1987; Hedges et al., 2001; Rex et al., 2006). However, hadal trenches ( 6000-11 $000 \mathrm{~m}$ below sea level) contradict this paradigm (Danovaro et al., 2003; Glud et al., 2013; Leduc et al., 2016; Wenzhöfer et al., 2016; Luo et al., 2017), as they act as depocenters of OM (Jahnke and Jahnke, 2000) and hotspots for microbial activity (Glud et al., 2013; Wenzhöfer et al., 2016; Liu et 
al., 2019). Indeed, OM availability is considered the major factor controlling the abundance, biomass, and diversity of life in the deep ocean (Danovaro et al., 2003; Ichino et al., 2015), whereas hydrostatic pressure appears to be an important and additional factor controlling biological activity in hadal trench systems (Jamieson et al., 2010; Tamburini et al., 2013). However, our understanding of the composition, sources, and lability of OM in marine trenches remains limited. According to Xu et al. (2018), the main sources of OM to the hadal zone include (1) the vertical sinking of particulate OM (POM), (2) the carrion falls of dead bodies, (3) inputs of terrestrial OM, (4) downslope transport of OM from continental slopes, and (5) in situ chemosynthetic production associated with cold seeps or hydrothermal vents. Several studies have highlighted the importance of POM sinking mainly from the euphotic zone (Stockton and DeLaca, 1982; Angel, 1984; Gooday et al., 2010). In fact, POM fluxes measured at $4000 \mathrm{~m}$ in the North Pacific Subtropical Gyre reveal that a seasonal export pulse can exceed the mean annual flux by $\sim 150 \%$ (Poff et al., 2021). However, it is unknown whether such pulses reach the hadal sediments (6000$11000 \mathrm{~m}$ ). Downslope transport, on the other hand, can be facilitated by trench topography and gravity (Jahnke et al., 1990; Fischer et al., 2009; Inthorn et al., 2006; Ichino et al., 2015) and/or by earthquakes (Glud et al., 2013; Kioka et al., 2019), as recently reported in the Japan Trench (Schwestermann et al., 2021). Independent of the main sources of OM, which are spatially and temporally variable, the channeling of allochthonous OM to the hadal zone should be facilitated by the characteristic V-shape cross-section of trenches, unique tectonic position in the ocean, and the physiography of the canyons that connect to coast systems (Itou et al., 2000, 2011; Bao et al., 2018). Additionally, autochthonous OM sources include in situ microbial biomass production (Smith, 2012; Nunoura et al., 2016; Ta et al., 2019; Hand et al., 2020), although their overall contribution as a secondary input to carbon budgets and energy flow in these systems remains poorly constrained (Grabowski et al., 2019). The spatial variations in community structure seen in benthic prokaryotic populations in hadal regions such as the Mariana, Japan, and Izu-Ogasawara trenches have been attributed to the variability of biogeochemical conditions, mainly nitrate and oxygen availability (Hiraoka et al., 2020), with benthic oxygen consumption exhibiting heterogeneity (Glud et al., 2021). Recent metagenomic data have revealed the presence of abundant heterotrophic microorganisms in sediments of the Challenger Deep (Nunoura et al., 2018), which are likely fueled by the endogenous recycling of available OM (Nunoura et al., 2015; Tarn et al., 2016). Furthermore, the abundance of prokaryotes in hadal depths can be influenced by dynamic depositional conditions (Schauberger et al., 2021), which in turn may be influenced by the intensity of propagating internal tides (Turnewitsch et al., 2014). All these factors likely alter the deposition, distribution, and composition of OM present in trench sediments.
An alternative approach to study microbial processes and the contribution of autochthonous OM is the use of cell membrane intact polar lipids (IPLs), which although less specific than genomic markers, allow for more quantitative estimates of microbial biomass in nature (e.g., Lipp et al., 2008; Schubotz et al., 2009; Cantarero et al., 2020). IPLs are composed of a polar head group typically attached to a glycerol backbone from which aliphatic chains are attached via ester and/or ether bonds (Sturt et al., 2004). Their structural diversity is given by the modifications found in the different components of their chemical structure (e.g., polar head groups can be comprised of phosphorous, nitrogen, sulfur, sugars, and amino acids), whereas aliphatic chains (alkyl or isoprenoidal) can vary in their length (number of carbon atoms) and their degree of unsaturation, methylation, hydroxylation, and cyclization (Van Mooy and Fredricks, 2010; Brandsma et al., 2012; Schubotz et al., 2013). In bacteria and eukaryotes, alkyl chains are most commonly linked via an ester bond to the sn-glycerol-3-phosphate backbone (Koga and Morii, 2007), although some bacteria are known to produce di- and tetraether lipids (Weijers et al., 2007). The variability of membrane chemical structures underlies the adaptability of microbial lifestyles to changing environmental conditions such as nutrients, temperature, oxygen, $\mathrm{pH}$, and pressure (DeLong and Yayanos, 1985; Somero, 1992; Van Mooy et al., 2009; Carini et al., 2015; Sebastián et al., 2016; Siliakus et al., 2017; Boyer et al., 2020). Furthermore, since eukaryotic and bacterial ester-bond IPLs are more labile than ether-bond counterparts (Logemann et al., 2011), they are suitable biomarkers to evaluate sources of labile OM in marine environments.

IPLs have been previously used as microbial markers in diverse marine settings, such as along strong redox gradients in the Black Sea (Schubotz et al., 2009) and the oxygen minimum zones (OMZs) of the eastern tropical Pacific (Schubotz et al., 2018; Cantarero et al., 2020) and the Arabian Sea (Pitcher et al., 2011), as well as in surface openocean waters of the eastern South Pacific (Van Mooy and Fredricks, 2010), the northwestern Atlantic (Popendorf et al., 2011b), and the Mediterranean Sea (Popendorf et al., 2011a), to name a few. Their utility as markers of microbial diversity and processes has also been tested in marine sediments (Liu et al., 2011, 2012; Sturt et al., 2004), such as along the Peru margin, equatorial Pacific, Hydrate Ridge, and Juan de Fuca Ridge (Lipp and Hinrichs, 2009a), and in subsurface sediment layers from the Peru margin (Biddle et al., 2006). However, to the best of our knowledge, no IPL studies have been reported for sediments of hadal trenches.

In this study, we investigate the chemical diversity and abundance of microbial IPLs as markers of one the most labile molecular fractions of OM in sediments of the deepest points of the Atacama Trench and compare them to IPL stocks in bathyal surface sediments $(\sim 500-1200 \mathrm{~m})$ and the overlying $700 \mathrm{~m}$ of the water column (Cantarero et al., 2020). More specifically, we evaluate possible IPL provenance (in 
situ vs. allochthonous production) and the presence of unique IPL signatures of the in situ microbial community as well as evidence for molecular adaptations to the extreme conditions of the hadal region.

\section{Material and methods}

\subsection{Study areas and sampling}

The Atacama Trench is located in the eastern tropical South Pacific (ETSP) along the Peru-Chile margin, and it underlies the eutrophic and highly productive Humboldt Current System (Angel, 1982; Ahumada, 1989), which includes the fourth largest (by volume) oxygen minimum zone (OMZ) in the world (Schneider et al., 2006). In this area, while there is minimal river runoff (Houston, 2006), winds can transfer dust from the adjacent continental desert (Angel, 1982). With an extension of $\sim 5900 \mathrm{~km}$, the Atacama Trench is the world's largest trench (Sabbatini et al., 2002), whereas it is geographically isolated from other trenches in the Pacific Ocean.

In this study, we investigated the diversity and abundance of bacterial and eukaryotic IPLs in a total of nine hadal surface $(0-1 \mathrm{~cm})$ and subsurface $(1-2$ and $2-3 \mathrm{~cm})$ sediments (three sites between 7734 and $8063 \mathrm{~m}$ water depth) collected during the HADES-SO261 cruise (March to April 2018) aboard the RV Sonne (Wenzhöfer, 2019) and seven bathyal surface sediments (seven sites; 529-1200 m water depth) collected during the ChiMeBo-SO211 cruise (2-29 November 2010) aboard the RV Sonne (Matys et al., 2017) (Table 1; Fig. 1). We compare our results against IPL results from the overlying water column $(0-700 \mathrm{~m})$ recently reported in Cantarero et al. (2020).

Sediment samples were collected using a multi-corer (MUC) equipped with twelve $60 \mathrm{~cm}$ long acrylic tubes (6$10 \mathrm{~cm}$ diameter for bathyal sediments and $9.5 \mathrm{~cm}$ diameter for hadal sediments). During the HADES expedition, an autonomous lander equipped with a Sea-Bird SBE-19 plus CTD and two Niskin bottles (30 L) was used to obtain hydrographic data down to $\sim 7850 \mathrm{~m}$. Hadal sediments from the HADES-SO261 cruise were stored at $4{ }^{\circ} \mathrm{C}$ until they were extruded and subsampled aboard at $1 \mathrm{~cm}$ resolution and then kept frozen at $-20^{\circ} \mathrm{C}$ until their processing in the laboratory. Further information about sample collection of bathyal and hadal sediments during the ChiMeBo-SO211 and HADESSO261 cruises can be found in Matys et al. (2017) and Wenzhöfer et al. (2019), respectively.

We compare our IPL results from surface sediment in the hadal and bathyal regions against samples from the overlying water column from the LowpHOX-2 cruise recently reported by Cantarero et al. (2020). This includes size-fractionated suspended OM (0.3-2.7 and 2.7-53 $\mu \mathrm{m})$ at two stations and from six water depths that are representative of the dominant biogeochemical zonation associated with the $\mathrm{OMZ}$ of this

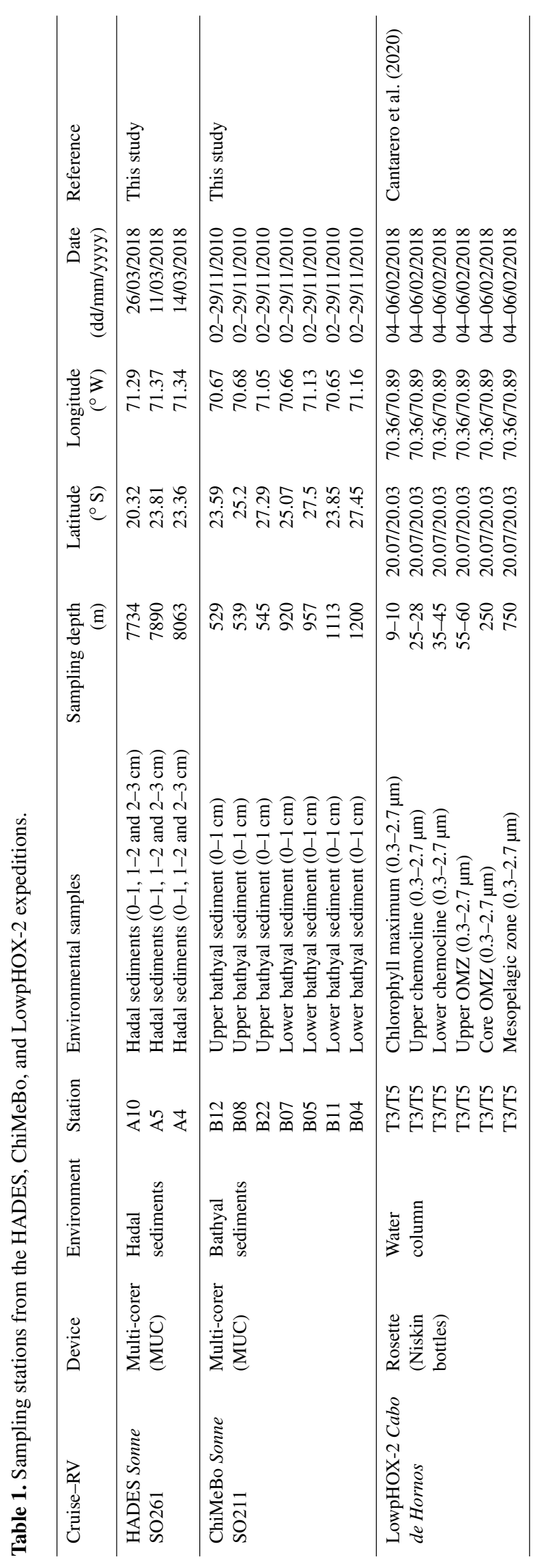

Biogeosciences, 19, 1395-1420, 2022 

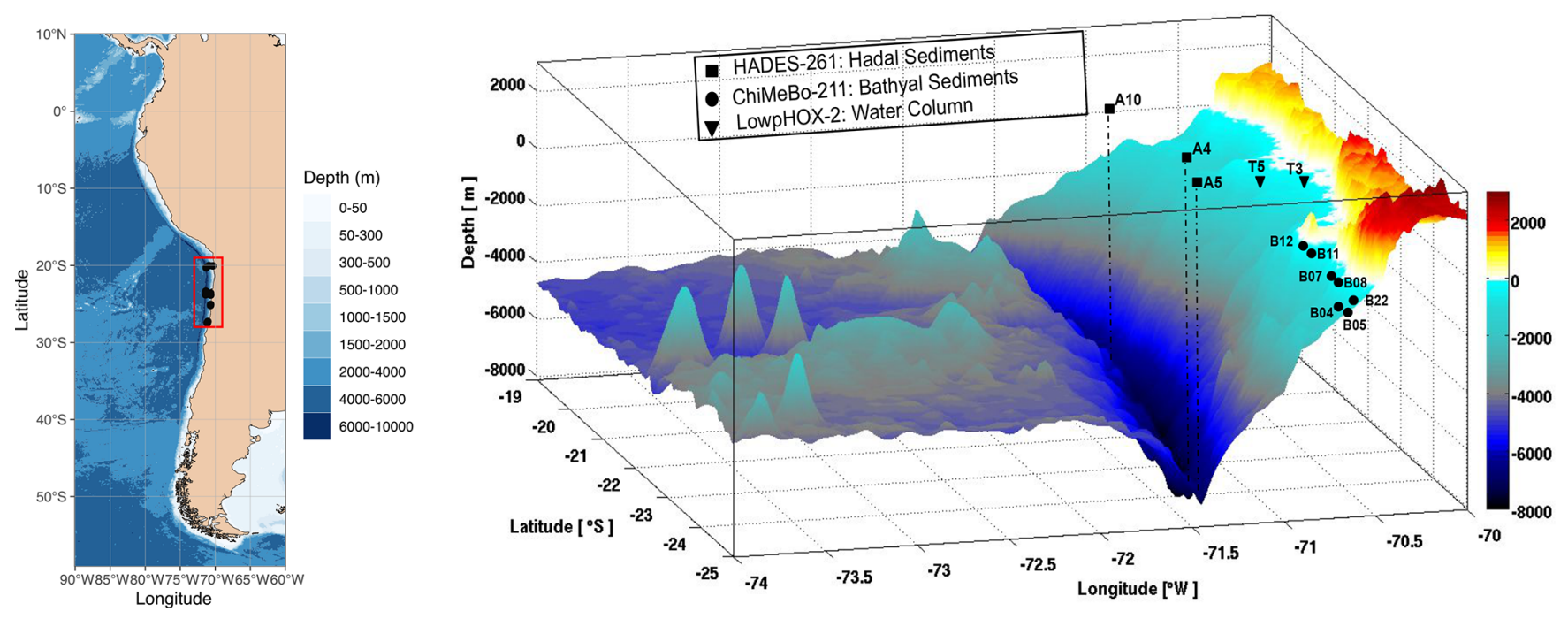

Figure 1. Three-dimensional map of the Atacama Trench showing the sampling locations of this study. The black squares indicate the hadal sediment sampling stations, the black circles indicate the bathyal sediment sampling stations from Matys et al. (2017), and the black triangles indicate water-column sampling stations from Cantarero et al. (2020).

region: chlorophyll maximum $(\sim 10 \mathrm{~m})$, upper chemocline $(\sim 25 \mathrm{~m})$, lower chemocline $(\sim 45 \mathrm{~m})$, upper OMZ $(\sim 60 \mathrm{~m})$, core OMZ $(\sim 250 \mathrm{~m})$, and mesopelagic zone $(\sim 750 \mathrm{~m})$ (see Table 1 and Cantarero et al., 2020, for further details).

\subsection{Analytical methods}

\subsubsection{Lipid extraction}

All samples were processed, extracted, and analyzed in the Organic Geochemistry Laboratory at the University of Colorado Boulder. Sediment samples were freeze-dried before extraction. Approximately $1-2 \mathrm{~g}$ of dry sediment was placed in a combusted glass centrifuge tube and extracted using a modified version (Wörmer et al., 2013) of the Bligh and Dyer extraction method (Bligh and Dyer, 1959) as detailed in Cantarero et al. (2020). Briefly, before extraction, we added $1 \mu \mathrm{g}$ of $\mathrm{C} 16 \mathrm{PAF}\left(\mathrm{C}_{26} \mathrm{H}_{54} \mathrm{NO}_{7} \mathrm{P}\right)$ to each sample as an internal standard. Samples were sequentially extracted using dichloromethane / $\mathrm{MeOH} /$ phosphate buffer $(1: 2: 0.8 v$ : $v: v ; 2 \times)$, dichloromethane / $\mathrm{MeOH} /$ trichloroacetic buffer $(1: 2: 0.8 v: v: v ; 2 \times)$, and dichloromethane / $\mathrm{MeOH}(1:$ $5 v: v ; 1 \times)$. After each addition, samples were vortexed for $30 \mathrm{~s}$, sonicated for $10 \mathrm{~min}$, and then centrifuged for $5 \mathrm{~min}$ at $2000 \mathrm{rpm}$. Each extraction was then transferred to a separatory funnel where a total lipid extract (TLE) was combined and then concentrated under a gentle $\mathrm{N}_{2}$ stream. Before analysis, the TLEs were resuspended in dichloromethane / methanol $(9: 1) v: v$ and filtered through a $0.45 \mu \mathrm{m}$ polytetrafluoroethylene (PTFE) syringe filter. The processing and extraction of bathyal sediments from the ChiMeBo-SO211 cruise and water-column samples from the LowpHOX-2 cruise has been reported by Matys et al. (2017) and Cantarero et al. (2020), respectively. TLEs were transferred into $2 \mathrm{~mL}$ vials with $200 \mu \mathrm{L}$ inserts and dissolved in $100 \mu \mathrm{L}$ of dichloromethane $/ \mathrm{MeOH}(9: 1, v: v)$.

\subsubsection{IPL analysis}

IPL were analyzed according to Wörmer et al. (2013) and as described in Cantarero et al. (2020) using a Thermo Scientific UltiMate 3000 high-performance liquid chromatograph (HPLC) coupled to a Q Exactive Focus Orbitrap quadrupole high-resolution mass spectrometer (HPLCHRMS) via electrospray ionization (ESI). The HPLC program comprised a flow rate of $0.4 \mathrm{~mL} \mathrm{~min}^{-1}$ using a mixture of two mobile phases: mixture A consisted of acetonitrile/dichloromethane $(75: 25, v: v)$ with $0.01 \%$ formic acid and $0.01 \% \mathrm{NH}_{4} \mathrm{OH}$; mixture $\mathrm{B}$ consisted of methanol/water $(50: 50, v: v)$ with $0.4 \%$ formic acid and $0.4 \% \mathrm{NH}_{4} \mathrm{OH}$. We used a linear gradient as follows: $1 \%$ mixture $\mathrm{B}(0-2.5 \mathrm{~min}), 5 \%(4 \mathrm{~min}), 25 \%$ mixture $\mathrm{B}$ (22.5 min), $40 \%$ mixture B (26.5-27.5 min), and the HPLC column was kept at $40^{\circ} \mathrm{C}$. Samples were injected $(10 \mu \mathrm{L})$ and dissolved in dichloromethane / methanol $(9: 1, v: v)$. IPLs were separated using a Waters Acquity BEH Amide column $(2.1 \times 150 \mathrm{~mm} ; 1.7 \mu \mathrm{m}$ particle size $)$ that enables classspecific separation based on their hydrophilic head group (Wörmer et al., 2013).

ESI settings comprised sheath gas $\left(\mathrm{N}_{2}\right)$ pressure 35 (arbitrary units), auxiliary gas $\left(\mathrm{N}_{2}\right)$ pressure 13 (arbitrary units), spray voltage $3.5 \mathrm{kV}$ (positive ion ESI), capillary temperature $265^{\circ} \mathrm{C}$, and S-lens RF level 55 (arbitrary units). The instrument was calibrated for mass resolution and accuracy using the Thermo Scientific Pierce LTQ Velos ESI Positive Ion Calibration Solution (containing a mixture of caffeine, 
MRFA, Ultramark 1621, and N-butylamine in an acetonitrile / methanol / acetic acid solution).

IPLs were identified on positive ionization mode, on both full scan and data-dependent $\mathrm{MS}^{2}$, based on their molecular weights as either protonated $(\mathrm{M}+\mathrm{H})^{+}$or ammonium $\left(\mathrm{M}+\mathrm{NH}_{4}\right)^{+}$adducts compounds, fragmentation patterns, and retention times, and they were compared against relevant literature (Sturt et al., 2004; Schubotz et al., 2009; Wakeham et al., 2012) and the internal database of the Organic Geochemistry Laboratory at the University of Colorado Boulder.

The peak areas of individual IPLs were integrated using the Thermo Fisher Scientific TraceFinder software using extracted ion chromatograms of their characteristic molecular ions. IPL abundances were determined with a combination of an internal standard ( $\mathrm{C}_{16} \mathrm{PAF}$, Avanti Polar Lipids) and an external calibration to a linear regression between peak areas and known concentrations of an IPL cocktail comprised of 17 different IPL classes across a five-point dilution series (0.001-2.5 ng $\mu \mathrm{L}$ ) (see Cantarero et al., 2020). Deuterated standards (Avanti Polar Lipids: d7-PC, d7-PG, d7-PE, and DGTS-d9) were used to correct for potential matrix effects on ionization efficiency. Despite the limited number of available deuterated standards, on average, we observed that the matrix effect accounts for a loss of $\sim 7 \pm 0.6 \%$ in ionization efficiency. Therefore, it is reasonable to assume a similar loss for other IPL classes, although this remains to be tested in future studies. We highlight the importance of using as many IPLs classes as possible to account for both differences in ionization efficiency and matrix effect when performing IPL quantification in environmental samples. The relative response factors followed the order MGDG $>$ DGTS $>$ DGTA $>$ PDME $>$ PME $>$ PG $>$ PC $>$ PE $>$ SQDG $>$ DGCC $>$ DGDG. Lipid classes were grouped into phospholipids (PG, phosphatidylglycerol; $\mathrm{PE}$, phosphatidylethanolamine; PC, phosphatidylcholine; and PME/PDME, phosphatidyl(di)methylethanolamine), glycolipids (MGDG, monoglycosyldiacylglycerol; DGDG, diglycosyldiacylglycerol; and SQDG, sulfoquinovosyldiacylglycerol), betaine lipids (DGTA, diacylglyceryl hydroxymethyl-trimethyl- $\beta$-alanine; DGTS, diacylglyceryl trimethylhomoserine; and DGCC, diacylglycerylcarboxy$\mathrm{N}$-hydroxymethyl-choline), and other lipids (glycosidic ceramides, Gly-Cer; PI, phosphatidylinositol; and OL, ornithine lipids). In addition, we use DAG to designate a diacylglycerol and AEG to designate an acyletherglycerol, and we describe short and long chains to refer to combined alkyl chains of $\mathrm{C}_{28-36}$ and $\mathrm{C}_{36-44}$, respectively (Rêzanka and Sigler, 2009; Schubotz et al., 2009; Brandsma., et al., 2012).

\subsection{Statistical analyses}

We used the Bray-Curtis similarity coefficient (Mirzaei et al., 2008) to produce hierarchical clustering of the abundance of classes and molecules of IPLs; two types of $p$ val- ues were available: approximately unbiased (AU) $p$ value and bootstrap probability (BP) value with the number of bootstrap replications of 10000 (Suzuki and Shimodaira, 2006). We performed non-metric multidimensional scaling (NMDS) (Warton et al., 2012) to examine the dissimilarity between the IPLs in each sample. The calculated distances to group centroids were based on the Bray-Curtis dissimilarity from the IPL abundance matrix, and the significance of the associations was determined by 999 random permutations. Significance tests of the multivariate dissimilarity between groups were made using analysis of similarity (ANOSIM), where complete separation and no separation among groups is suggested by $R=1$ and $R=0$, respectively (Clarke and Gorley, 2015). Statistical differences in the numbers of carbon atoms and double bonds were identified by ANOVA and Tukey's HSD (honestly significant difference) post hoc test. We used similarity of percentage (SIMPER) analysis to identify the percentage contributions of IPLs which accounted for $>90 \%$ of the similarity within each cluster. The multivariate statistical analyses as well as other statistical analyses were calculated using the vegan package (Oksanen et al., 2013) of open-source software $\mathrm{R}$ version 3.6.2 within the ggplots package (Warnes et al., 2015).

\section{Results}

\subsection{Hydrographic conditions}

A physical-chemical characterization of the water column during the ChiMeBo-SO211, LowpHOX-2, and HADESSO261 cruises has been reported in Matys et al. (2017), Cantarero et al. (2020) and Vargas et al. (2021), and Fernández-Urruzola et al. (2021), respectively. Briefly, the potential-temperature-salinity-dissolved oxygen $(\theta-s-$ $\mathrm{O}_{2}$ ) diagrams revealed an oxygenated and well-mixed water mass occupying the deeper parts of the Atacama Trench (Fig. S1). However, the upper $1000 \mathrm{~m}$ shows variability in temperature $\left(12-23^{\circ} \mathrm{C}\right)$, salinity (34.4-34.8 psu), and oxygen $(0.5-267 \mu \mathrm{M})$. More stable physical-chemical conditions are apparent in the mesopelagic and bathypelagic zone of the Atacama Trench between 1000 and $4000 \mathrm{~m}$ (temperature $\sim 2.3^{\circ} \mathrm{C}$, salinity $\sim 34.6$ psu, oxygen $\sim 120.6 \mu \mathrm{M}$ ). Below $4000 \mathrm{~m}$, average conditions were characterized by a potential temperature $\sim 1.8^{\circ} \mathrm{C}$, salinity $\sim 34.7 \mathrm{psu}$, and oxygen $\sim 143 \mu \mathrm{M}$ (Fig. S1).

\subsection{IPLs in surface sediments of the Atacama trench}

\subsubsection{Distribution of IPL classes by polar head groups}

The 16 sediment samples from bathyal and hadal regions statistically grouped into four clusters based on their dominant polar head group classes (Fig. 2, chemical structures in Fig. S2). Clusters 1 and 2 had approximately unbiased (AU) $p$ values of $91 \%$ and $88 \%$, respectively. Cluster 3 had the 
highest AU $p$ value of $\geq 97 \%$, whereas cluster 4 had the lowest $\mathrm{AU} p$ value of $61 \%$. The cluster analysis revealed a degree of spatial heterogeneity between bathyal and hadal depths and between the top three centimeters of hadal sediments, which results in the lack of a clear separation between hadal and bathyal environments. In addition, the 0 $1 \mathrm{~cm}$ hadal sediments at the A4 station were un-clustered, consistent with a distinct distribution pattern of IPL classes. Cluster 1, composed of only hadal samples from three different stations and depths, included phospholipids as the most abundant IPL class (Fig. 2). Clusters 2, 3, and 4, composed of mixed bathyal and hadal samples, were mostly differentiated by changes in the relative abundances of non-phosphorous IPLs including betaine classes. The un-clustered sample was characterized by the lowest relative abundance of phospholipids and the highest relative abundance of betaine lipids (especially DGCC).

\subsubsection{Distribution of individual IPLs}

An overview of the most important IPLs contributing to dissimilarity between samples was obtained through a SIMPER analysis based on the Bray-Curtis coefficient within each cluster (Fig. 3). Samples in cluster 1 were on average $59.5 \%$ similar, with 14 individual IPLs contributing $50.6 \%$ of the total similarity. This cluster exhibited a high contribution of PE-DAG $(32: 1,33: 1$, and $34: 2)$, PG-DAG (36:2), and DGCC (26:0, $27: 0$, and $28: 0)$ molecules (Table 2). Additionally, this cluster exhibited a large diversity of PC molecules, although with a low relative abundance (Fig. 3). Samples in cluster 2, on the other hand, which includes mainly bathyal stations, were on average $58.8 \%$ similar and exhibited a high contribution of PC-DAG (35:0, $32: 1,36: 2,33: 1$, and $35: 1$ ) (Table 2). While this cluster shows a wide range of molecules, including PG, PE, and MGDG, their relative contributions are low (Fig. 3). Samples in cluster 3 were on average $57.3 \%$ similar and included three bathyal and one hadal stations. This cluster exhibited a high contribution of DGCC (42:6) and PC-DAG (35: 0, 33 : 2, $30: 1$, and $29: 2$ ) molecules (Table 2). Samples in cluster 4 were on average $63.6 \%$ similar and exhibited a high contribution of PC-DAG $(30: 2,33: 2)$, DGCC (42:6), MGDG (28:0), and PE-DAG (33:2 and $31: 2)$ molecules (Table 2). The un-cluster sample (hadal sediment of $0-1 \mathrm{~cm}$ at A4 station) is mainly composed by the DGCC $42: 6$ (Fig. 3). In general, phospholipids showed a wide distribution and were found across all sediment samples. The total dissimilarity between cluster 1 and 2 was 59.17\%, with PC-DAG-35:0, PE-DAG-32: 1, PI-AR, PG-DAG-36: 2, DGCC $27: 0$, PCDAG-36 : 2, PC-DAG-34 :1, PC-DAG-32: 1, DGCC $26: 0$, and PC-DAG-35: 1 contributing $32.4 \%$ of it (Table 2). The total dissimilarity between cluster 1 and 3 was $60.7 \%$, with DGCC $42: 6$, PC-DAG-35 : 0, PI-AR, PE $32: 1$, PG-DAG$36: 2$, DGCC $27: 0$ and $26: 0$, and PC-DAG-33:2 contributing $38.1 \%$ of it (Table 2). The total dissimilarity be- tween cluster 1 and 4 was $62.5 \%$, with DGCC $42: 6$, PCDAG-30 : 2, PE $32: 1$, PC-DAG-35 :0, PG-DAG-36 : 2, PCDAG-33 : 2, and DGCC $27: 0$ contributing $37.62 \%$ of it (Table 2).

\subsection{Distribution of alkyl chains based on length and degree of unsaturation}

The difference in the total number of acyl carbon atoms in both alkyl chains, rather than in individual fatty acids, and in the number of acyl double bonds within each cluster is shown in Fig. 4. Statistical differences of IPLs classes within each cluster were obtained through a Tukey HSD post hoc test at a significant level of $p<0.05$ (Fig. 4a, b). The average number of carbon atoms in the diglyceride moieties of IPLs in the cluster 1 presented that DGCC, MGDG, others, PC, and PG were all distinct from one another $(n=283 ; P<0.05$; Fig. 4a). PG and others were characterized by relatively long alkyl chains (35-36 C atoms, respectively) and DGCC for shorter alkyl chains (32 $\mathrm{C}$ atoms). In general, cluster $1 \mathrm{ex}-$ hibited a wide range of chain lengths among DAGs (28-36 $\mathrm{C}$ atoms). Cluster 2 showed a narrower range than cluster 1 (30-36 C atoms). This cluster also displayed no statistical difference $(p>0.05)$ among IPL classes (Fig. 4a), following pairwise comparisons with Tukey's HSD post hoc test, despite the wide range of DGCC structures. For cluster 3, while it exhibited low variability in betaine lipids, it also revealed the highest number of carbon atoms in DGCCs (42). On the contrary, cluster 4 presented high viability in DGCCs, which did not exceed 42 carbon atoms. Within the phospholipid class, PG showed the highest number of carbon atoms in all clusters; the mean we observed was 34 carbon atoms and a range of 32-37 (Fig. 4a). The un-cluster sample (hadal sediment of $0-1 \mathrm{~cm}$ at A4 station) was characterized by relatively longer alkyl chains (up to $42 \mathrm{C}$ atoms) than cluster 1 (Fig. 4a).

Overall, the degree of unsaturation (i.e., number of double bounds) within clusters was variable (Fig. 4b). Cluster 1 predominantly consisted of fully saturated and monounsaturated IPLs, except for PG that showed 2 double bonds on average. In cluster 2, the fatty acids of DGCCs were distinctly variable, although they exhibited 2 unsaturations on average. A similar pattern was observed in DGDGs with an average of 2.5 unsaturations (Fig. 4b). DGTS, MGDG, PC, and SQDG showed zero to 1 unsaturation, whereas DGTA, PE, and PG exhibited between 1 and 2.5 unsaturations. Cluster 3 showed more than 5 unsaturations on average for DGCC, unlike other IPL classes that did not exceed 2 unsaturations. In cluster $4, \mathrm{PG}$ and DGCC presented $\sim 3$ and $\sim 5$ unsaturations on average. Also, on average, DGDG and SQDG exhibited 2 unsaturations, MGDG and others were mono-unsaturated, and DGTS was saturated (Fig. 4b). Additionally, the ratio of total unsaturated fatty acids to total saturated fatty acids in IPLs increased from (on average) $\sim 0.9$ in 
Table 2. Similarity percentage (SIMPER) analysis. The average abundance and contribution of IPLs that explain the main differences among the sediment samples is based on the hierarchical clusters shown in Fig. 2.

\begin{tabular}{|c|c|c|c|c|c|}
\hline \multicolumn{6}{|c|}{$\begin{array}{l}\text { Group cluster } 1 \\
\text { Cluster } 1: \text { average similarity }=59.53\end{array}$} \\
\hline IPLs & $\begin{array}{l}\text { Average } \\
\text { cluster } 1\end{array}$ & $\begin{array}{l}\text { Average } \\
\text { similarity }\end{array}$ & $\begin{array}{r}\text { Similarity/ } \\
\text { SD }\end{array}$ & $\begin{array}{r}\text { Contribution } \\
(\%)\end{array}$ & $\begin{array}{r}\text { Cumulative } \\
(\%)\end{array}$ \\
\hline PI-AR & 0.06 & 4.76 & 2.46 & 7.99 & 7.99 \\
\hline PE-DAG-32: 1 & 0.06 & 4.37 & 1.45 & 7.34 & 15.33 \\
\hline PG-DAG-36 : 2 & 0.05 & 3.79 & 2 & 6.36 & 21.69 \\
\hline PE-DAG-33 : 1 & 0.03 & 2.06 & 33.49 & 3.45 & 25.14 \\
\hline PE-DAG-34 : 2 & 0.03 & 1.89 & 1.74 & 3.17 & 28.31 \\
\hline DGCC-26: 0 & 0.04 & 1.84 & 2.04 & 3.09 & 31.4 \\
\hline PC-DAG-30 : 1 & 0.03 & 1.76 & 2.21 & 2.96 & 34.36 \\
\hline DGCC-27:0 & 0.04 & 1.74 & 1.8 & 2.93 & 37.3 \\
\hline PE-DAG-30 : 0 & 0.02 & 1.7 & 13.1 & 2.86 & 40.15 \\
\hline PE-DAG-32 : 2 & 0.02 & 1.39 & 1.07 & 2.34 & 42.49 \\
\hline PC-DAG-35: 0 & 0.02 & 1.31 & 1.52 & 2.2 & 44.69 \\
\hline DGCC-28: 0 & 0.02 & 1.22 & 1.96 & 2.05 & 46.74 \\
\hline PC-DAG-26: 0 & 0.02 & 1.18 & 1.46 & 1.99 & 48.73 \\
\hline PC-DAG-28: 0 & 0.02 & 1.14 & 1.59 & 1.91 & 50.63 \\
\hline \multicolumn{6}{|l|}{ Group cluster 2} \\
\hline IPLs & $\begin{array}{l}\text { Average } \\
\text { cluster } 2\end{array}$ & $\begin{array}{l}\text { Average } \\
\text { similarity }\end{array}$ & $\begin{array}{r}\text { Similarity/ } \\
\text { SD }\end{array}$ & $\begin{array}{r}\text { Contribution } \\
(\%)\end{array}$ & $\begin{array}{r}\text { Cumulative } \\
(\%)\end{array}$ \\
\hline PC-DAG-35: 0 & 0.08 & 5.63 & 7.54 & 9.58 & 9.58 \\
\hline PC-DAG-32: 1 & 0.03 & 3.12 & 31.24 & 5.3 & 14.88 \\
\hline PC-DAG-36 : 2 & 0.05 & 2.74 & 1.13 & 4.67 & 19.55 \\
\hline PC-DAG-33 : 1 & 0.02 & 2.04 & 10.17 & 3.46 & 23.01 \\
\hline PC-DAG-35: 1 & 0.03 & 1.63 & 4.48 & 2.77 & 25.78 \\
\hline PI-AR & 0.02 & 1.61 & 3.9 & 2.74 & 28.53 \\
\hline MGDG-32: 1 & 0.02 & 1.44 & 1.35 & 2.45 & 30.98 \\
\hline PE-DAG-32 : 1 & 0.02 & 1.38 & 5.03 & 2.35 & 33.33 \\
\hline PE-DAG-34 : 2 & 0.02 & 1.38 & 2.75 & 2.35 & 35.68 \\
\hline PE-DAG-32 : 2 & 0.02 & 1.22 & 2.79 & 2.08 & 37.76 \\
\hline PC-DAG-32:0 & 0.01 & 1.14 & 5.69 & 1.94 & 39.69 \\
\hline PG-DAG-36 : 2 & 0.02 & 1.1 & 3.23 & 1.87 & 41.57 \\
\hline PG-DAG-35 : 2 & 0.02 & 1.09 & 1.23 & 1.86 & 43.43 \\
\hline PC-DAG-34 : 1 & 0.04 & 1.06 & 0.41 & 1.8 & 45.23 \\
\hline PC-DAG-30 : 1 & 0.01 & 1.05 & 7.23 & 1.79 & 47.02 \\
\hline PC-DAG-32 : 2 & 0.01 & 0.95 & 11.7 & 1.61 & 48.64 \\
\hline PC-DAG-29 : 2 & 0.01 & 0.95 & 2.69 & 1.61 & 50.25 \\
\hline \multicolumn{6}{|l|}{$\begin{array}{l}\text { Group cluster } 3 \\
\text { Cluster 3: averag }\end{array}$} \\
\hline IPLs & $\begin{array}{l}\text { Average } \\
\text { cluster } 3\end{array}$ & $\begin{array}{l}\text { Average } \\
\text { similarity }\end{array}$ & $\begin{array}{r}\text { Similarity/ } \\
\text { SD }\end{array}$ & $\begin{array}{r}\text { Contribution } \\
(\%)\end{array}$ & $\begin{array}{r}\text { Cumulative } \\
(\%)\end{array}$ \\
\hline DGCC-42: 6 & 0.16 & 12.84 & 6.72 & 22.4 & 22.4 \\
\hline PC-DAG-35 : 0 & 0.08 & 4.78 & 1.14 & 8.33 & 30.74 \\
\hline PC-DAG-33 : 2 & 0.03 & 2.07 & 1.19 & 3.61 & 34.35 \\
\hline PC-DAG-30 : 1 & 0.03 & 1.96 & 1.82 & 3.42 & 37.77 \\
\hline PC-DAG-29: 2 & 0.03 & 1.79 & 1.2 & 3.12 & 40.89 \\
\hline PI-AR & 0.05 & 1.69 & 1.09 & 2.95 & 43.84 \\
\hline MGDG-32 : 1 & 0.01 & 1.22 & 7.66 & 2.14 & 45.98 \\
\hline PE-DAG-32 : 1 & 0.01 & 1.18 & 10.45 & 2.05 & 48.03 \\
\hline PC-DAG-30 : 0 & 0.02 & 1.13 & 1.22 & 1.97 & 50 \\
\hline
\end{tabular}


Table 2. Continued.

\begin{tabular}{|c|c|c|c|c|c|}
\hline \multicolumn{6}{|c|}{$\begin{array}{l}\text { Group cluster } 1 \\
\text { Cluster } 1 \text { : average similarity }=59.53\end{array}$} \\
\hline IPLs & $\begin{array}{l}\text { Average } \\
\text { cluster } 1\end{array}$ & $\begin{array}{l}\text { Average } \\
\text { similarity }\end{array}$ & $\begin{array}{r}\text { Similarity/ } \\
\text { SD }\end{array}$ & $\begin{array}{r}\text { Contribution } \\
(\%)\end{array}$ & $\begin{array}{r}\text { Cumulative } \\
\qquad(\%)\end{array}$ \\
\hline \multicolumn{6}{|c|}{$\begin{array}{l}\text { Group cluster } 4 \\
\text { Cluster } 4 \text { : average similarity }=63.64\end{array}$} \\
\hline IPLs & $\begin{array}{l}\text { Average } \\
\text { cluster } 2\end{array}$ & $\begin{array}{l}\text { Average } \\
\text { similarity }\end{array}$ & $\begin{array}{r}\text { Similarity/ } \\
\text { SD }\end{array}$ & $\begin{array}{r}\text { Contribution } \\
(\%)\end{array}$ & $\begin{array}{r}\text { Cumulative } \\
(\%)\end{array}$ \\
\hline PC-DAG-30 : 2 & 0.12 & 9.04 & & 14.21 & 14.21 \\
\hline DGCC-42: 6 & 0.14 & 8.91 & & 13.99 & 28.2 \\
\hline PI-AR & 0.05 & 4.14 & & 6.5 & 34.71 \\
\hline PC-DAG-33 : 2 & 0.04 & 3.71 & & 5.83 & 40.54 \\
\hline MGDG-28 : 0 & 0.04 & 3.44 & & 5.41 & 45.95 \\
\hline PE-DAG-33 : 2 & 0.03 & 2.52 & & 3.97 & 49.92 \\
\hline PE-DAG-31: 2 & 0.03 & 2.14 & & 3.37 & 53.28 \\
\hline
\end{tabular}

\begin{tabular}{|c|c|c|c|c|c|c|}
\hline \multicolumn{7}{|c|}{$\begin{array}{l}\text { Groups cluster } 1 \text { and cluster } 2 \\
\text { Average dissimilarity }=59.17\end{array}$} \\
\hline IPLs & $\begin{array}{l}\text { Average } \\
\text { cluster } 1\end{array}$ & $\begin{array}{l}\text { Average } \\
\text { cluster } 2\end{array}$ & $\begin{array}{r}\text { Average } \\
\text { dissimilarity }\end{array}$ & $\begin{array}{r}\text { Dissimilarity/ } \\
\text { SD }\end{array}$ & $\begin{array}{r}\text { Contribution } \\
(\%)\end{array}$ & $\begin{array}{r}\text { Cumulative } \\
(\%)\end{array}$ \\
\hline PC-DAG-35:0 & 0.02 & 0.08 & 3.18 & 1.34 & 5.37 & 5.37 \\
\hline PE-DAG-32: 1 & 0.06 & 0.02 & 2.35 & 1.73 & 3.98 & 9.35 \\
\hline PI-AR & 0.06 & 0.02 & 2.21 & 1.74 & 3.73 & 13.08 \\
\hline PG-DAG-36 : 2 & 0.05 & 0.02 & 1.98 & 1.64 & 3.35 & 16.43 \\
\hline DGCC-27 : 0 & 0.04 & 0 & 1.93 & 1 & 3.26 & 19.69 \\
\hline PC-DAG-36 : 2 & 0.01 & 0.05 & 1.79 & 1.57 & 3.02 & 22.71 \\
\hline PC-DAG-34 : 1 & 0 & 0.04 & 1.79 & 1.03 & 3.02 & 25.73 \\
\hline PC-DAG-32: 1 & 0.01 & 0.03 & 1.36 & 5.58 & 2.3 & 28.03 \\
\hline DGCC-26: 0 & 0.04 & 0.01 & 1.34 & 0.95 & 2.27 & 30.3 \\
\hline PC-DAG-35 : 1 & 0.01 & 0.03 & 1.27 & 0.9 & 2.15 & 32.45 \\
\hline PE-DAG-33 : 1 & 0.03 & 0.01 & 1.02 & 1.2 & 1.73 & 34.18 \\
\hline PC-DAG-33: 1 & 0 & 0.02 & 0.96 & 7.61 & 1.63 & 35.8 \\
\hline DGCC-28:0 & 0.02 & 0 & 0.93 & 1.28 & 1.57 & 37.37 \\
\hline PC-AEG-34 : 3 & 0.02 & 0 & 0.9 & 1.03 & 1.52 & 38.89 \\
\hline PE-DAG-34 : 2 & 0.03 & 0.02 & 0.88 & 1.2 & 1.49 & 40.38 \\
\hline MGDG-32 : 1 & 0 & 0.02 & 0.83 & 1.81 & 1.4 & 41.78 \\
\hline PC-DAG-30 : 1 & 0.03 & 0.01 & 0.83 & 1.15 & 1.4 & 43.18 \\
\hline PG-DAG-34 : 2 & 0.02 & 0 & 0.77 & 1.05 & 1.3 & 44.48 \\
\hline PE-DAG-33 : 0 & 0.02 & 0 & 0.76 & 1.11 & 1.29 & 45.77 \\
\hline PG-DAG-35 : 1 & 0.02 & 0.01 & 0.74 & 1.22 & 1.26 & 47.03 \\
\hline PE-DAG-34 : 1 & 0.02 & 0 & 0.74 & 2.06 & 1.25 & 48.27 \\
\hline PC-DAG-26:0 & 0.02 & 0 & 0.72 & 1.74 & 1.21 & 49.48 \\
\hline DGCC-30 : 0 & 0 & 0.01 & 0.68 & 1.32 & 1.15 & 50.64 \\
\hline
\end{tabular}


Table 2. Continued.

\begin{tabular}{|c|c|c|c|c|c|c|}
\hline \multicolumn{7}{|c|}{$\begin{array}{l}\text { Groups cluster } 1 \text { and cluster } 3 \\
\text { Average dissimilarity }=60.69\end{array}$} \\
\hline IPLs & $\begin{array}{l}\text { Average } \\
\text { cluster } 1\end{array}$ & $\begin{array}{l}\text { Average } \\
\text { cluster } 3\end{array}$ & $\begin{array}{r}\text { Average } \\
\text { dissimilarity }\end{array}$ & $\begin{array}{r}\text { Dissimilarity/ } \\
\text { SD }\end{array}$ & $\begin{array}{r}\text { Contribution } \\
(\%)\end{array}$ & $\begin{array}{r}\text { Cumulative } \\
(\%)\end{array}$ \\
\hline DGCC-42: 6 & 0 & 0.16 & 8.02 & 3.2 & 13.21 & 13.21 \\
\hline PC-DAG-35:0 & 0.02 & 0.08 & 3.05 & 1.87 & 5.02 & 18.23 \\
\hline PI-AR & 0.06 & 0.05 & 2.66 & 1.6 & 4.39 & 22.62 \\
\hline PE-DAG-32: 1 & 0.06 & 0.01 & 2.49 & 1.74 & 4.1 & 26.72 \\
\hline PG-DAG-36 : 2 & 0.05 & 0.02 & 1.9 & 1.49 & 3.14 & 29.86 \\
\hline DGCC-27 : 0 & 0.04 & 0.01 & 1.84 & 0.97 & 3.03 & 32.89 \\
\hline DGCC-26:0 & 0.04 & 0.01 & 1.59 & 1.12 & 2.62 & 35.52 \\
\hline PC-DAG-33 : 2 & 0 & 0.03 & 1.58 & 1.7 & 2.61 & 38.12 \\
\hline PE-DAG-34 : 2 & 0.03 & 0.01 & 1.13 & 1.35 & 1.86 & 39.98 \\
\hline PE-DAG-33 : 1 & 0.03 & 0.01 & 1.07 & 1.33 & 1.76 & 41.75 \\
\hline PC-AEG-34 : 3 & 0.02 & 0 & 0.95 & 1.08 & 1.57 & 43.31 \\
\hline PC-DAG-29: 2 & 0.02 & 0.03 & 0.95 & 1.88 & 1.56 & 44.87 \\
\hline DGCC-28: 0 & 0.02 & 0 & 0.9 & 1.25 & 1.49 & 46.36 \\
\hline PC-DAG-30 : 1 & 0.03 & 0.03 & 0.87 & 1.35 & 1.43 & 47.79 \\
\hline PE-DAG-33 : 0 & 0.02 & 0 & 0.76 & 1.07 & 1.26 & 49.05 \\
\hline PG-DAG-34 : 2 & 0.02 & 0.01 & 0.76 & 1.1 & 1.26 & 50.3 \\
\hline \multicolumn{7}{|c|}{$\begin{array}{l}\text { Groups cluster } 1 \text { and cluster } 4 \\
\text { Average dissimilarity }=62.47\end{array}$} \\
\hline IPLs & $\begin{array}{l}\text { Average } \\
\text { cluster } 1\end{array}$ & $\begin{array}{l}\text { Average } \\
\text { cluster } 4\end{array}$ & $\begin{array}{r}\text { Average } \\
\text { dissimilarity }\end{array}$ & $\begin{array}{r}\text { Dissimilarity/ } \\
\text { SD }\end{array}$ & $\begin{array}{r}\text { Contribution } \\
(\%)\end{array}$ & $\begin{array}{r}\text { Cumulative } \\
(\%)\end{array}$ \\
\hline DGCC-42 : 6 & 0 & 0.14 & 6.99 & 2.57 & 11.19 & 11.19 \\
\hline PC-DAG-30 : 2 & 0.01 & 0.12 & 5.66 & 3.64 & 9.06 & 20.24 \\
\hline PE-DAG-32: 1 & 0.06 & 0 & 3.17 & 2.09 & 5.07 & 25.31 \\
\hline PC-DAG-35:0 & 0.02 & 0.04 & 2.22 & 1.6 & 3.55 & 28.86 \\
\hline PG-DAG-36 : 2 & 0.05 & 0.01 & 2.12 & 1.64 & 3.4 & 32.27 \\
\hline PC-DAG-33: 2 & 0 & 0.04 & 1.9 & 15.16 & 3.04 & 35.3 \\
\hline DGCC-27 : 0 & 0.04 & 0.02 & 1.45 & 0.78 & 2.32 & 37.62 \\
\hline PE-DAG-34 : 2 & 0.03 & 0 & 1.35 & 1.44 & 2.16 & 39.78 \\
\hline PI-AR & 0.06 & 0.05 & 1.3 & 1.6 & 2.08 & 41.86 \\
\hline DGCC-26:0 & 0.04 & 0.01 & 1.26 & 0.89 & 2.02 & 43.88 \\
\hline DGDG-34 : 2 & 0 & 0.03 & 1.25 & 1.17 & 2 & 45.88 \\
\hline PE-DAG-31 : 2 & 0 & 0.03 & 1.21 & 4.58 & 1.93 & 47.81 \\
\hline PE-DAG-33 : 1 & 0.03 & 0.01 & 1.2 & 1.46 & 1.92 & 49.73 \\
\hline PE-DAG-33 : 3 & 0 & 0.02 & 1.16 & 4.61 & 1.86 & 51.59 \\
\hline
\end{tabular}

all water-column samples ( $2-76$ bar) to $\sim 2.7$ in the bathyal (54-113 bar) and hadal sediments (777-810 bar) (Fig. 5).

\subsection{Unique IPLs in hadal sediments of the Atacama Trench}

Water-column particles and bathyal-hadal sediments shared 242 (96.1\%) IPL structures (Fig. 6a), while hadal sediments and water-column particles shared $14(0.02 \%)$, and hadal and bathyal sediments shared $55(3.6 \%)$. Of all the analyzed IPLs reported in this study, eight of them were unique to the Atacama Trench sediments and are not present in shallower sediments or the overlying water column. They include five glycolipids (SQDG-42 : 11, SQDG-23 : 0, DGDG-35 : 1, DGDG-35 : 2 and DGDG-37:1), two phosphatidylinositols (PI-diOH-Ext-AR and PI-OH-AR), and one ornithine lipid (OL-37:6). While unique to hadal sediments, their total concentration was low $(\sim 53.32 \mathrm{ng}$ per gram of sediment), and they contributed $\sim 0.00012 \%$ of the total IPL pool (Fig. 6a). We then performed a cluster analysis to compare IPLs in deep-sea surface sediments against IPLs reported in the overlying water column (Cantarero et al., 2020; Fig. 6b). Cluster 1 comprised samples from the core OMZ in the free-living fraction (AU $p$ value of $100 \%$ ). Cluster 2 comprised samples from both the upper and lower oxyclines $(\sim 14-60 \mathrm{~m})$ as well as from the chlorophyll maximum (AU 


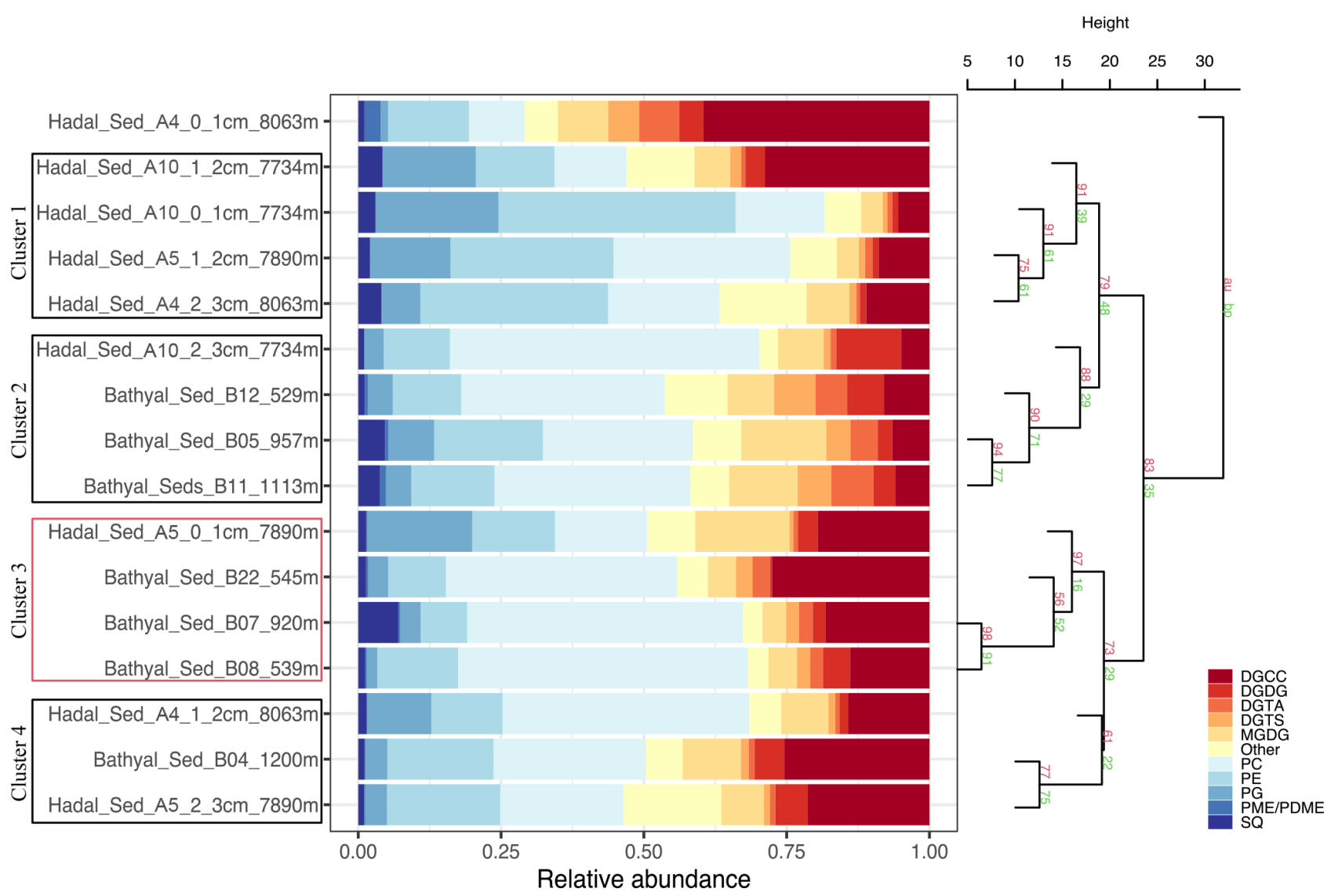

Figure 2. Cumulative bar charts of the fractional abundance of IPL classes in each surface sediment sample from the bathyal and hadal regions (left panel). Samples were grouped according to arithmetic mean (UPGMA) hierarchical clustering based on Euclidean distances. The $p$ values are shown at branches, with AU in red and BP in green (right panel). Clusters 3 with an AU $\geq 95 \%$ confidence are indicated by the red rectangles (left) and are considered to be strongly supported by the data.

$p$ value of $99 \%)$. Cluster 3 comprised bathyal and hadal samples (AU $p$ value of $99 \%$ ). Cluster 4 mostly comprised the deepest water-column sample (mesopelagic region at $750 \mathrm{~m}$ ) and hadal samples (AU $p$ value of $98 \%$; Fig. 6b). We also compared IPLs in hadal and bathyal sediments against the pool of IPLs reported as diagnostic of the planktonic community inhabiting the chlorophyll maximum in the upper water column (Cantarero et al., 2020) and thus assess their export and stability through their transit to the deep sea. Notably, these IPLs from this region of the water column only represent $\sim 0.001 \%-0.005 \%$ and $0.002 \%-0.03 \%$ of the total IPL pool in hadal and bathyal sediments, respectively (Fig. S3).

We found a high degree of heterogeneity in total IPL concentrations among sites and different sediment levels $(0-1$, $1-2,2-3 \mathrm{~cm})$ in the Atacama Trench, which were an order of magnitude higher than bathyal sediments (see Fig. S4a, b). Hadal sediments at station A10 (7734 m) showed a large range of phospholipid concentrations $(\sim 47-2698 \mathrm{ng}$ per gram of sediment) (Fig. S4b). Although the highest total IPL abundances were observed at hadal station A10 (Fig. S4b), the greatest diversity in IPL composition was observed in the
$0-1 \mathrm{~cm}$ of the hadal station A4, previously referred to as unclustered (see Fig. 2). The most abundant IPL class in hadal sediments was phospholipids, PCs ( 41-2698 ng per gram of sediment), PEs ( $\sim 26-1813$ ng per gram of sediment), and PGs (5-937 ng per gram of sediment). The concentration of IPLs normalized by total organic carbon (TOC) (ng IPL per gram of TOC) showed maximum values in the hadal station A10 ( $497 \mu$ IPL per gram of TOC), followed by lower values in the hadal stations A5 and A4 of $\sim 291$ and $\sim 75 \mu \mathrm{g}$ IPL per gram of TOC, respectively (Fig. S5).

\section{Discussion}

\subsection{Potential sources of phospholipids}

\section{PG (phosphatidylglycerol)}

Phospholipids are common constituents of cellular membranes in most microorganisms (Ratledge and Wilkinson, 1988). Since PGs play an essential role in photosynthesis (Wada and Murata, 2007), they have therefore been mainly 


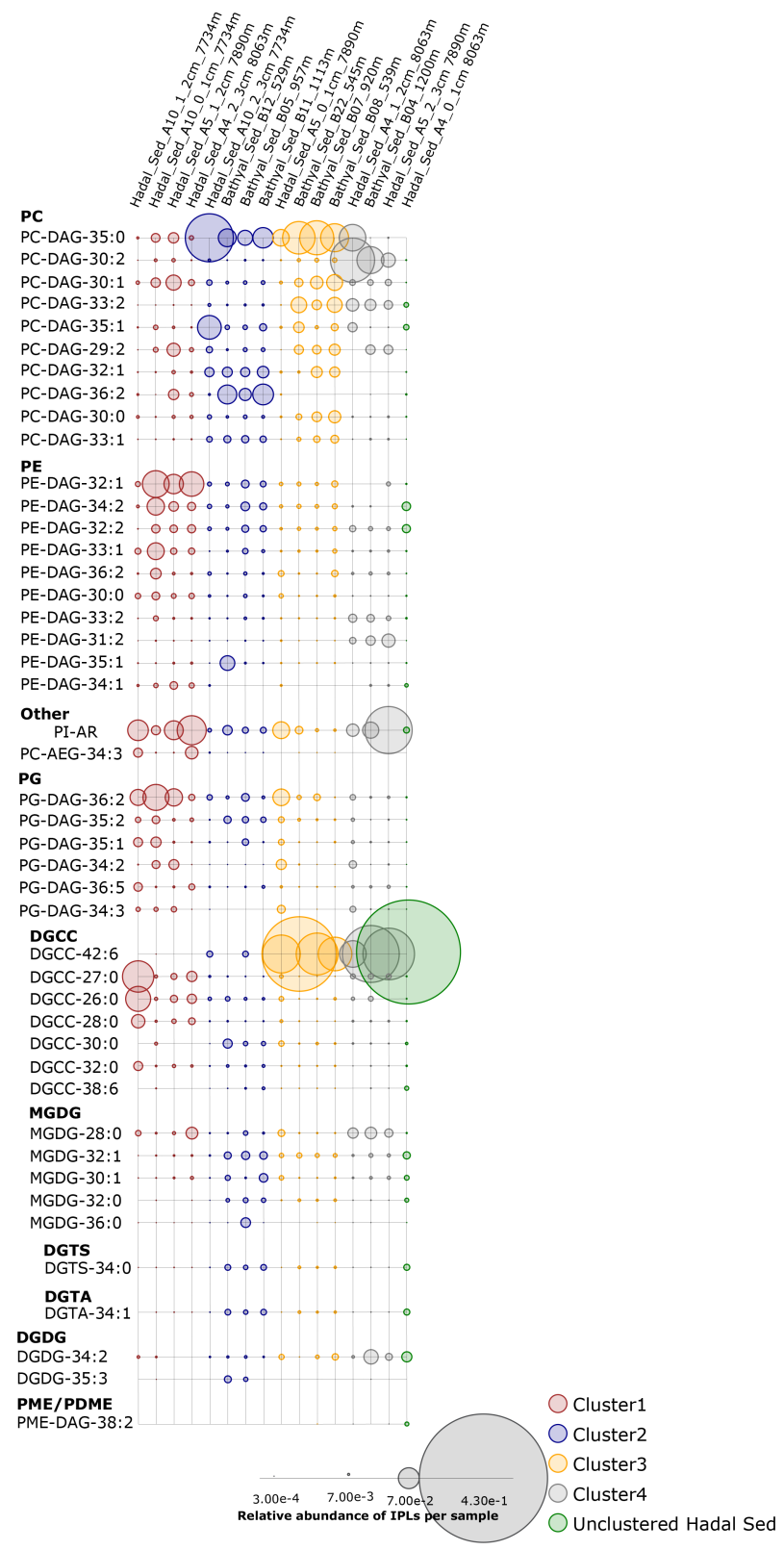

Figure 3. Relative abundance of individual IPLs contributing most of the dissimilarity between the four clusters shown in Fig. 2. Sampling stations are organized left to right and are shown using the same order from hierarchical clusters in Fig. 2, whereas IPL classes are organized from top to bottom. The circle size is proportional to the relative abundance of IPLs in each sample (bottom panel).

identified in algal and bacterial photoautotrophs (Dowhan, 1997; Sato et al., 2000; Gombos et al., 2002). However, their biological origin is highly diverse and also includes heterotrophic bacteria (Oliver and Colwell, 1973; Van Mooy et al., 2009; Popendorf et al., 2011b; Carini et al., 2015; Sebastián et al., 2016), methylotrophs (Batrakov and Nikitin, 1996), methanotrophic bacteria (Makula, 1978), Pelagibacter ubique (Van Mooy et al., 2009), and barophilic bacteria (e.g., DB21MT-2 and DB21MT-5) isolated from sediments from the Mariana Trench (Fang et al., 2000).

The hierarchical cluster analysis on variations in the relative abundance of PGs suggests that several compounds maintained a similar proportion in bathyal and hadal sediments, which differs from the water column (Fig. S6). Most PGs in the bathyal and hadal sediments have long acyl carbon chains $\left(\mathrm{C}_{34}-\mathrm{C}_{41}\right)$, and they show odd- and evennumbered polyunsaturated fatty acids (Fig. S6). The average chain lengths of even-numbered $n-\mathrm{C}_{18}, n-\mathrm{C}_{20}$, and $n$ $\mathrm{C}_{22}$ fatty acids, mostly in PCs and PGs, are indicative of algal inputs (Kaneda, 1991; Thompson, 1996; Bergé and Barnathan, 2005; Brandsma et al., 2012). However, since these PGs were not dominant in the water column, a source from deeper environments is likely. Specifically, PG-DAG-36:2, PG-DAG-35 :2, PG-DAG-36 : 5, PG-DAG-37 :2, and PGDAG-41 $: 4$ are the dominant constituents of this IPL class in hadal-bathyal sediments (Figs. 7, S6). PG-DAG-36: 2 has been described in surface waters of the North Sea and also detected in picoeukaryotes (Brandsma et al., 2012) and in heterotrophic bacteria in surface waters of the open South Pacific Ocean (Van Mooy and Fredricks, 2010). However, these PGs are not dominant in the water column near the Atacama Trench (Cantarero et al., 2020). On the other hand, PG-DAG$35: 2$, PG-DAG-36 : 5, PG-DAG-37 :2, and PG-DAG-41 : 4 are not commonly reported in water-column studies. Thus, it is possible that PGs present in the Atacama Trench sediments derive from in situ microbial production, although downslope and lateral transport of labile OM cannot be ruled out. PGDAG-36: 2 (Fig. 3) is the PG contributing most to the dissimilarity within the cluster containing only hadal sediments (cluster 1 in Fig. 2). Thus, this lipid appears to be more representative of in situ microbial production in this environment.

\section{PE (phosphatidylethanolamine)}

PE and its methylated derivatives (PME, PDME) have been predominantly reported in membranes of diverse bacterial sources, including heterotrophic bacteria (Van Mooy and Fredricks, 2010; Schubotz et al., 2018), nitrifying/denitrifying bacteria (Goldfine and Hagen, 1968), sulfate-reducing bacteria (Rütters et al., 2001; Sturt et al., 2004), sulfur-oxidizing bacteria (Barridge and Shively, 1968; Imhoff, 1995; Wakeham et al., 2012), methanotrophic bacteria (Makula, 1978; Sturt et al., 2004), and barophilic bacteria (Fang et al., 2000).

PEs showed a similar distribution in bathyal and hadal sediments (Fig. S7), where they are dominated by longchain $\left(\mathrm{C}_{36-44}\right)$ polyunsaturated fatty acids, contrary to the shorter chains $\left(\mathrm{C}_{28}-36\right)$ of saturated and monounsaturated fatty acids present in the water column. PE-DAG-32: 1 , PEDAG-32: 2, and PE-DAG-33:1 are the dominant PE compounds of bathyal and hadal sediments (Fig. 7). These IPLs have been previously reported in heterotrophic bacteria (Van Mooy and Fredricks, 2010; Brandsma et al., 2012). On the 

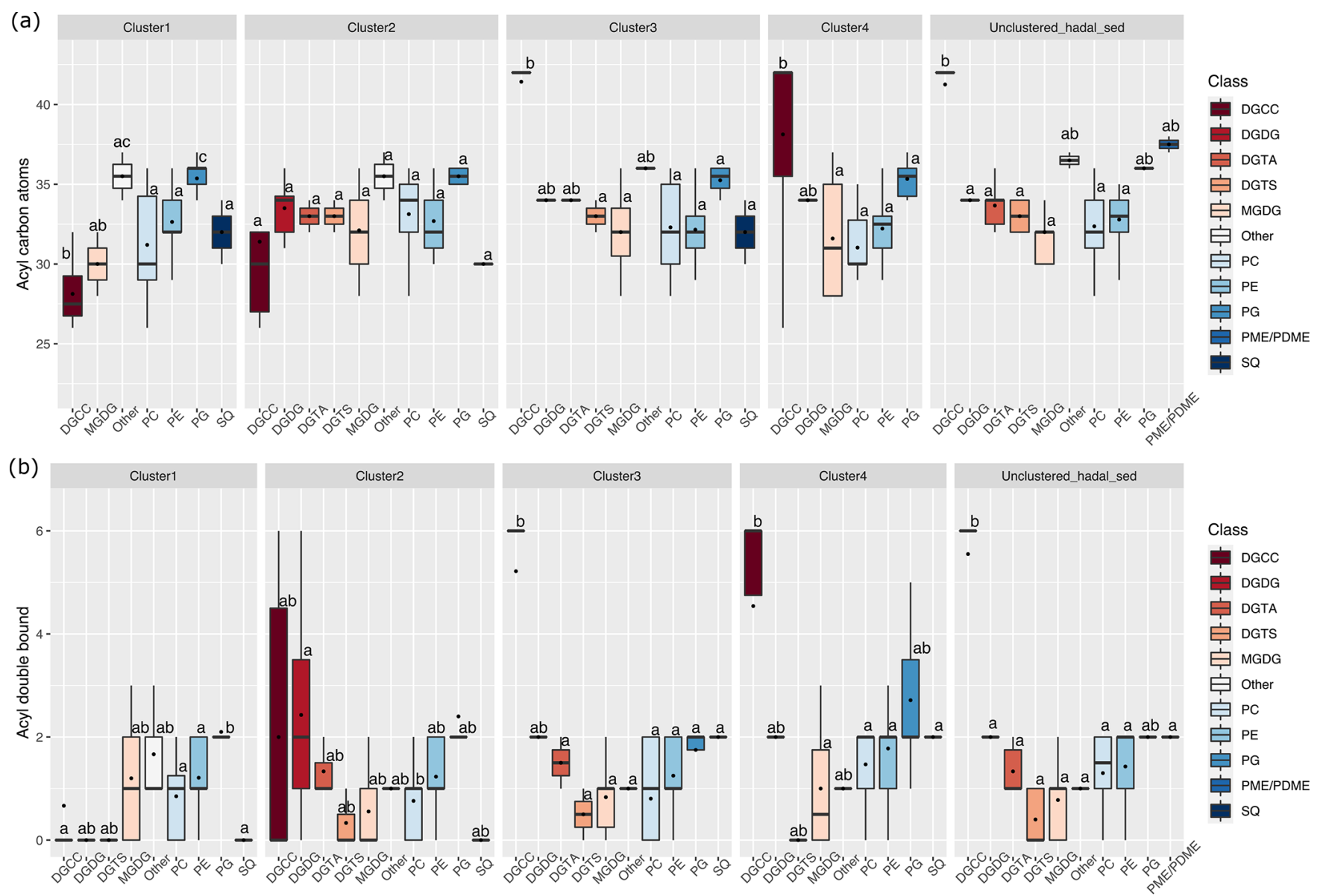

Class of IPLs

Figure 4. Total number of acyl carbon atoms (a) and acyl double bonds (b) in IPL classes across the distinct clusters shown in Fig. 2. The letters "a" and "b" indicate the presence of statistically distinct groups $(p<0.05)$ from both ANOVA and post hoc Tukey HSD tests, respectively.

other hand, fatty acids in PEs including monounsaturated and polyunsaturated (e.g., $\mathrm{C}_{20: 5}$ and $\mathrm{C}_{22: 6}$ ) have been reported in barophilic bacteria isolated from sediments from the Mariana Trench (Fang et al., 2000). Thus, although we cannot confidentially rule out other sources, it is possible that PEs present in the AT sediments predominantly derive from in situ production by barophilic heterotrophic bacteria. PE-DAG-32: 1 , PE-DAG-32 : 2, and PE-DAG-33: 1 (Fig. 3) are the PEs that contributed most to the dissimilarity within the cluster containing only hadal sediment samples (cluster 1 in Fig. 2). Thus, this cluster appears to be representative of in situ microbial production in this environment.

\section{PC (phosphatidylcholine)}

PCs were amongst the most diverse (43 structures: Fig. S8) and abundant phospholipid class in hadal sediments (Fig. S4). PC is the major membrane-forming phospholipid in eukaryotes (Lechevalier, 1988; Sohlenkamp et al., 2003;
Van Mooy et al., 2006; Van Mooy and Fredricks, 2010). Additionally, PC has been reported to be a major DAG in zooplankton, from protozoa to copepods and krill (Patton et al., 1972; Mayzaud et al., 1999; Lund and Chu, 2002). However, genomic data indicate that more than $10 \%$ of all bacteria possess the genetic machinery for PC biosynthesis (Sohlenkamp et al., 2003). PC has also been reported in nitrifying bacteria (Lam et al., 2007), photoheterotrophic bacteria (Koblížek et al., 2006; Van Mooy et al., 2006), and barophilic bacteria (Fang et al., 2000). In surface sediments of the Black Sea $(2000 \mathrm{~m})$, PCs were related to algal material rapidly exported from surface waters (Schubotz et al., 2009).

Hadal and bathyal sediments, in addition to two OMZ core stations, were clustered in the PC class (AU $p$ value of $97 \%$; Fig. S8). This cluster showed PCs with long $\left(\mathrm{C}_{33-38}\right)$ and polyunsaturated fatty acids (up to 10 unsaturations). The dominant constituents were PC-DAG-35 : 0, PC-DAG-30 : 2, PC-DAG-30 $: 1$, PC-DAG-33 $: 2$, PC-DAG-35 $: 1$, PC-DAG$29: 2$, PC-DAG-32 : 1, and PC-DAG-36 $: 2$ (Figs. 7, S8). PC- 


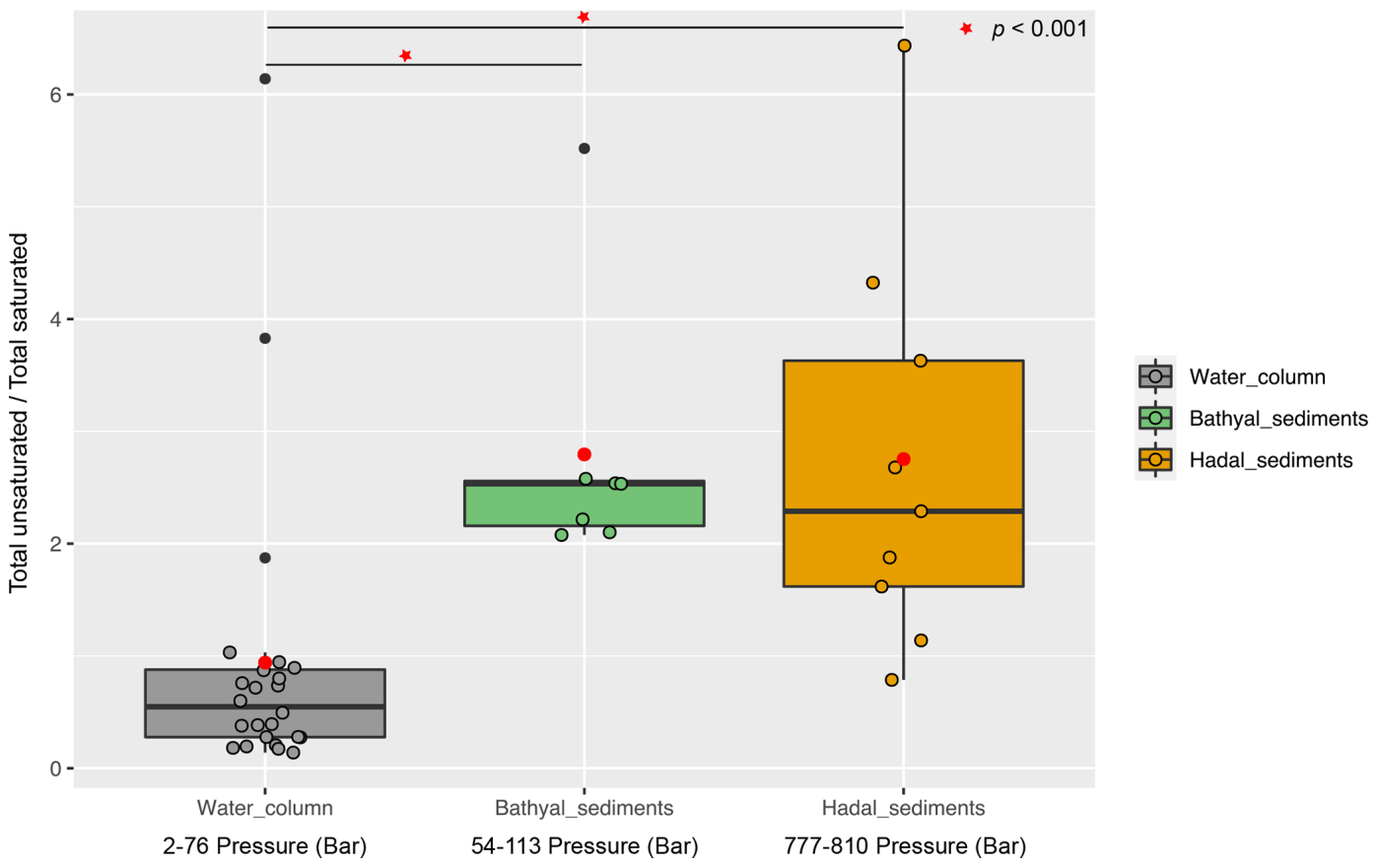

Figure 5. Boxplot showing the ratio of total unsaturated fatty acids to total saturated fatty acids derived from IPLs present in water-column samples (Cantarero et al., 2020) and sediments of the Atacama Trench (this study). Red circles indicate the average value in each environment. The Wilcoxon test ( $p$ value $<0.001$ ) indicates that sediments have statistical ratios higher than the water column (horizontal lines and red starts).

DAG-36: 2 and PC-DAG-30: 1 have been associated with phytoplankton detritus (Schubotz et al., 2009) and bacteria (Brandsma et al., 2012), whereas PC-DAG-32: 1 has been associated with picoeukaryotes (Brandsma et al., 2012).

Since the most abundant PCs in cluster 1 have not been reported as dominant structures in any specific environment before, they are possibly produced in situ, although downslope and/or lateral transport cannot be ruled out. Among bacteria, those membranes reported to contain PC belong to the alpha and gamma subgroups of the Proteobacteria (Sohlenkamp et al., 2003). Given that these bacterial groups are abundant in trench samples from Puerto Rico (Eloe et al., 2011), the Mariana Trench (Nunoura et al., 2015), and recently in the Atacama Trench (Schauberger et al., 2021), it is possible that PCs present in high abundance in the Atacama Trench are consistent with high abundance of Proteobacteria in these regions. Given their general known association and abundance in Atacama Trench sediments (Fig. S4), they likely derive primarily from bacterial but also possibly from fungi or metazoan sources that have not yet been studied and to a lesser extent from phytoplankton. Indeed, fungal strains isolated from the water column and sediment in the ESTP off Chile reported high levels of polyunsaturated fatty acids and PCs (Gutiérrez et al., 2020), whereas a high fungal diversity associated with denitrification potential was reported in the Yap Trench (Gao et al., 2020). The latter suggests that eu- karyotic PCs in hadal sediments could be much more diverse in origin than previously thought.

\section{PME/PDME (phosphatidyl(di)methylethanolamine)}

PME/PDMEs have been observed in association with methanotrophic bacteria (Makula, 1978; Goldfine, 1984; Fang et al., 2000); sulfide-oxidizing bacteria (Barridge and Shively, 1968); sulfate-reducing bacteria, mainly Desulfobulbus spp. (Rossel et al., 2011), Proteobacteria (Oliver and Colwell, 1973; Goldfine, 1984); and barophilic bacteria from the Mariana Trench (Fang et al., 2000). Additionally, the occurrence of PME-DEG at some hadal stations suggests the presence of sulfate-reducing bacteria (Rütters et al., 2001; Sturt et al., 2004).

PME/PDMEs exhibited their lowest abundance $(\sim 10 \mathrm{ng}$ per gram of sediment) in sediment samples compared to other phospholipids (Fig. S4b). In the bathyal and hadal sediments they were clustered (AU $p$ value of $97 \%$ ) and dominated by PDME-DAG-33 : 1, PME-DAG-37 :2, PME-DAG$34: 2$, PME-DAG-31 : 1, and PME-DEG-33: 0 (Fig. S9a). PME-DEG-33:0 has been shown to correlate with high $\mathrm{NO}_{2}^{-}$in the overlying water column of this area (Cantarero et al., 2020), which could suggest a potential association with denitrification processes. These structures have also been reported in the deep chemocline of the Cariaco Basin (Wakeham et al., 2012), suggesting a potential chemoautotrophic and/or heterotrophic source. The distribution of these com- 
(a)

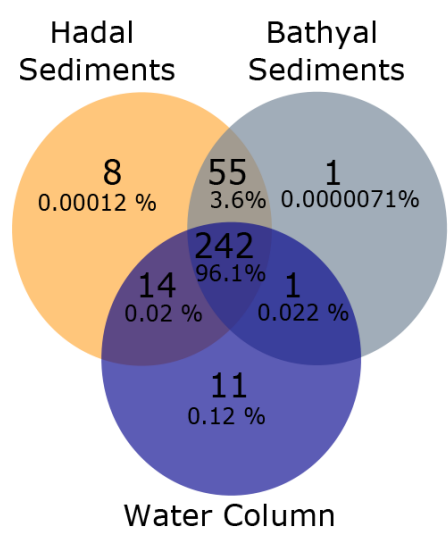

(b)

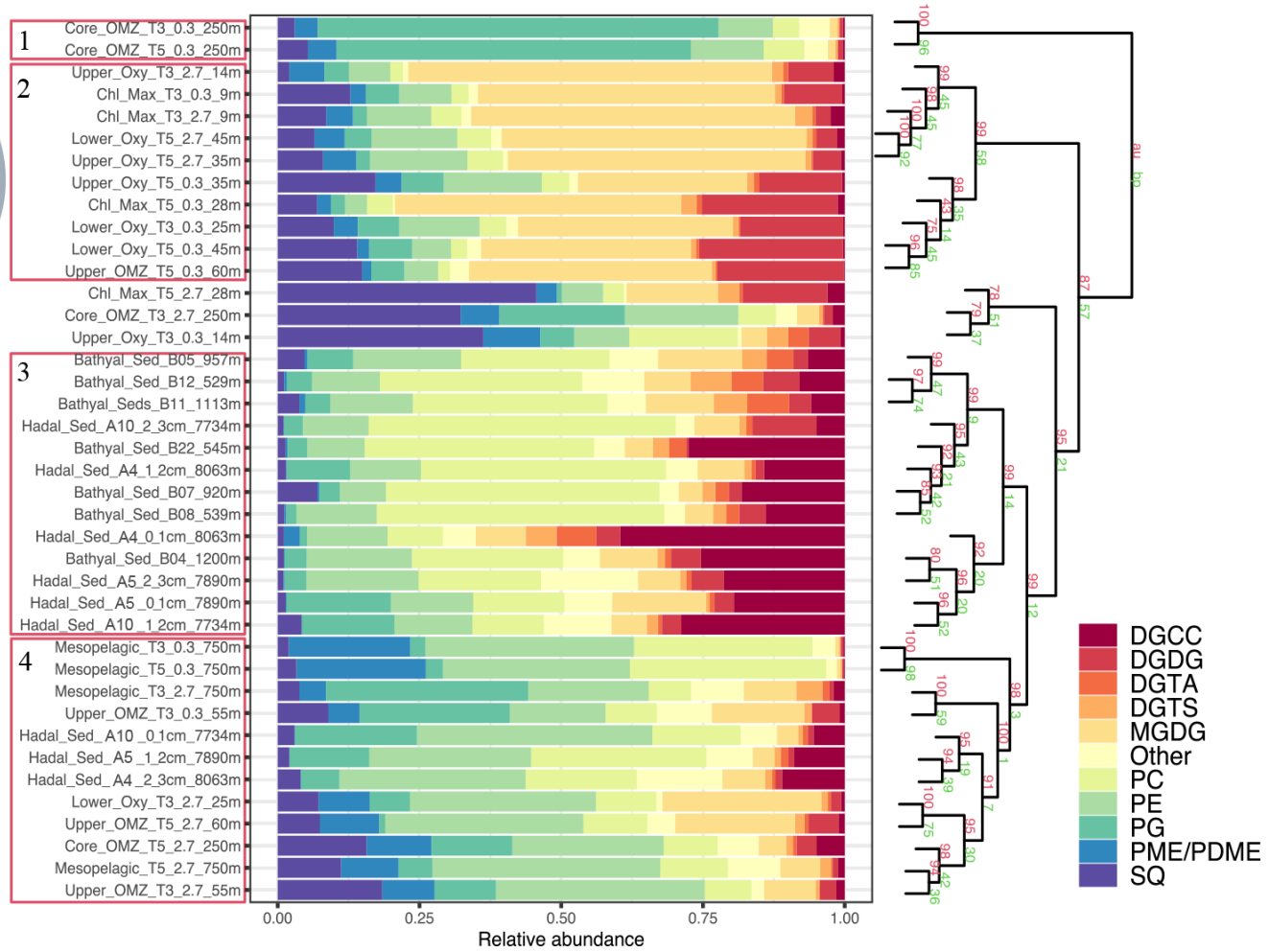

Figure 6. Comparison of IPLs in bathyal and hadal sediments (this study) and the overlying water column (Cantarero et al., 2020). (a) Venn diagram showing the number and percentage of unique and shared IPL molecules between these three environments. (b) Cumulative bar charts of IPL fractional abundances in each sample. Samples were grouped according to arithmetic mean (UPGMA) hierarchical clustering based on Euclidean distances. The cluster analysis on the right-hand side shows approximately unbiased (AU) and bootstrap probability (BP) in red and green numbers, respectively, whereas $p$ values are shown at branching points. Clusters with AU $\geq 95 \%$ confidence are highlighted in red on the left-hand side.

pounds is different from the water column, which is dominated by the saturated PME-32:0, PME-DAG-30:0, and PME-DAG-31 : 0 (Figs. S9a and S16; Cantarero et al., 2020). Thus, and similar to other lipid classes, they most likely derive from in situ production in hadal sediments rather than from the water column, although other sources such as downslope and/or lateral transport cannot be ruled out. No particular PME/PDMEs were found to contribute to the dissimilarity between the cluster containing only hadal sediment samples (cluster 1 in Fig. 2) and other sediment samples.

\subsection{Potential sources of glycolipids}

\section{MGDG (monoglycosyldiacylglycerol)}

Due to their dominant occurrence in chloroplast thylakoid membranes (Murata and Siegenthaler, 1998) and particularly in cyanobacteria (Heinz, 1977; Harwood, 1998; Wada and Murata, 2007; Van Mooy and Fredricks, 2010), but also in heterotrophic bacteria (Popendorf et al., 2011b), MGDGs are probably the most abundant IPLs on earth (Gounaris and Barber, 1983).

The hierarchical cluster suggests that several MGDG compounds maintained a similar proportion in bathyal (AU $p$ value of $90 \%$ ) and hadal (AU $p$ value of $98 \%$ ) sediments (Fig. S10). The most abundant MGDGs in the bathyal and hadal sediments were MGDG-28 :0, MGDG-32:1, MGDG$30: 1$, MGDG-32:0, and MGDG-37 :3. MGDG-28 $: 0$ and MGDG-30: 1 are ubiquitous along the oxycline of the overlying OMZ (Fig. 7; Cantarero et al., 2020). In addition, MGDG-32: 1 has been previously reported in waters of the eastern South Pacific (Van Mooy and Fredricks, 2010). Thus, the occurrence of these MGDGs in sediment could indicate at least some export of labile OM from surface waters. On the other hand, MGDG-37: 3 does not appear to be a dominant structure in any specific environment in the literature, which suggests a likely in situ production. 


\section{DGDG (diglycosyldiacylglycerol)}

DGDGs are commonly found in membranes of eukaryotic algae and cyanobacteria (Wada and Murata, 1998; Sakurai et al., 2006; Kalisch et al., 2016). DGDGs clustered together in bathyal and hadal sediments (AU p value of $96 \%$ ), whereas their distribution differed from the water column (Fig. S11). The most abundant DGDGs in hadal and bathyal sediments of the Atacama Trench was DGDG-34 : 2 (Fig. 7), which has been previously reported in cyanobacterial strains isolated (da Costa et al., 2020) but has not been previously reported as abundant in the water column. In contrast, DGDG-30 : 0 , which is widely distributed in the water column of this region (Cantarero et al., 2020), is consistently present in hadal and bathyal sediment samples although at very low abundances (Fig. 7). Thus, although DGDGs account for less than $\sim 5 \%$ of the total IPL pool (Fig. 6b), except for station A10 (2$3 \mathrm{~cm}$ ) where they reach $\sim 10 \%$, their presence in bathyal and hadal sediments is indicative of at least some export of labile OM from surface waters.

\section{SQDG (sulfoquinovosyldiacylglycerol)}

SQDGs are predominantly produced by photoautotrophs (Van Mooy et al., 2006; Popendorf et al., 2011b), including various groups of diatoms, brown and green algal chloroplast membranes (Harwood, 1998), and cyanobacteria (Siegenthaler, 1998; Wada and Murata, 1998). SQDGs have also been found in bacteria from the $\alpha$ - and $\gamma$-proteobacterial lineages (Benning, 1998). In the overlying water column of the Atacama Trench, Cantarero et al. (2020) suggested a higher contribution of SQDGs from cyanobacteria than algae. Also, SQDGs found in the deep Atlantic (down to $\sim 4000-5000 \mathrm{~m}$ ) appear to indicate a source and export from surface waters (Gašparović et al., 2018).

SQDGs showed a consistent distribution in bathyal and hadal sediments, where they are dominated by long-chain $\left(\mathrm{C}_{36-44}\right)$ fatty acids (Fig. S12). This is contrasting to their distribution in the overlying water column where they are dominated by shorter-chain $\left(\mathrm{C}_{28-36}\right)$ saturated fatty acids (Cantarero et al., 2020). SQDG-30 : 0, SQDG-32 : 0, SQDG$30: 2$, and SQDG-38:4 were the dominant SQDG constituents of bathyal and hadal sediments (Fig. 7). SQDG-30 : 0 and SQDG-30: 2 have been reported in bacteria in North Sea surface waters (Brandsma et al., 2012), in cyanobacteria of the eastern subtropical South Pacific (Van Mooy and Fredricks, 2010), and in plankton detritus from surface sediments of the Black Sea (Schubotz et al., 2009). Furthermore, SQDG-30: 0 is abundant in surface waters of our study area, and SQDG-38:4 has been correlated with $\mathrm{NO}_{3}^{-}$(Cantarero et al., 2020). The observed differences in the distribution of SQDGs in deep sediments compared to the water column suggests an in situ production of previously poorly characterized compounds, in addition to at least some export from surface waters.

\subsection{Potential biological sources of betaine lipids}

\section{DGTS (diacylglyceryl trimethylhomoserine)}

DGTSs have diverse biological origins, being found in a wide range of eukaryotes (Sato, 1992; Dembitsky, 1996; Kato et al., 1997; Van Mooy et al., 2009), photoheterotrophic bacteria (Benning et al., 1995; Geiger et al., 1999), photoautotrophic bacteria (Popendorf et al., 2011b) including cyanobacteria (Řezanka et al., 2003), and members of the $\alpha$-Proteobacteria subdivision (López-Lara et al., 2003). Schubotz et al. (2018) showed DGTS with varying fatty acid compositions in the OMZ system of the eastern tropical North Pacific, especially in OMZ waters, indicating that these compounds can be biosynthesized by a wider range of source organisms than previously thought.

Consistent with other IPL classes, DGTSs of the bathyal and hadal samples were grouped in the same cluster (AU $p$ value of $98 \%$ ) and differed from the water column (Fig. S13). However, several DGTSs are shared between surface waters $(9-60 \mathrm{~m})$ and deep sediments. Indeed, the most abundant DGTSs in bathyal and hadal sediments (DGTS34 : 0, DGTS-32 : 1, DGTS-26 : 0, DGTS-34 : 1, DGTS-32 : 0 , and DGTS-25: 0; Figs. 7, S13) are also prominent in the chlorophyll maximum in the eastern subtropical South $\mathrm{Pa}$ cific (Van Mooy and Fredricks, 2010; Cantarero et al., 2020). Therefore, their presence in hadal sediments suggest the export of some labile OM from the euphotic zone, although we cannot rule out other sources.

\section{DGTA (diacylglyceryl hydroxymethyl-trimethyl- $\beta$-alanine)}

DGTAs have been widely reported in eukaryotic phytoplankton (Araki et al., 1991; Dembitsky, 1996; Cañavate et al., 2017), mainly in diatoms (Volkman et al., 1989; Zhukova, 2005; Gómez-Consarnau et al., 2007), and are also especially abundant in cultures of prymnesiophytes and cryptophytes (Kato et al., 1997). DGTAs have also been found in cyanobacteria (Brandsma et al., 2012) and heterotrophic bacteria (Popendorf et al., 2011a; Sebastián et al., 2016).

DGTAs in bathyal and hadal sediments are mainly composed of longer $\left(\mathrm{C}_{28}-\mathrm{C}_{42}\right)$ and polyunsaturated (1-12) fatty acids compared to those present in the shallowest region of the overlying water column, composed of shorter and saturated fatty acids (Fig. S14). In the overlying water column, these compounds are associated with relatively high chlorophyll and $\mathrm{O}_{2}$ concentrations (Cantarero et al., 2020), similar to North Sea surface waters (Brandsma et al., 2012). To the best of our knowledge, the dominant DGTAs in hadal and bathyal sediments (Figs. 7, S14) have not been previously reported as dominant IPLs in other environments. Whereas no specific biological sources in hadal sediments are known, the structures containing between 30 and 38 carbon atoms might be characteristic of this type of environment. 


\section{DGCC}

(diacylglycerylcarboxy-N-hydroxymethyl-choline)

Our knowledge of DGCC sources is limited. They have been found in membranes of prymnesiophyte algae (Kato et al., 1994), mainly in Pavlova lutheria (Kato et al., 1994; Eichenberger and Gribi, 1997) and in E. huxleyi (Volkman et al., 1989; Pond and Harris, 1996; Van Mooy and Fredricks, 2010). Additionally, they have also been reported in the diatom Thalassiosira pseudonana (Van Mooy et al., 2009).

The most abundant IPL from the entire data set of bathyal and hadal sediments is DGCC-42: 6 (Figs. 7, S15). This is the compound with the largest number of $\mathrm{C}$ atoms (42) and unsaturation (6) in all IPLs detected in this study. DGCCs with long-chain, polyunsaturated fatty acids (i.e., $\mathrm{C}_{38: 6}$, $\mathrm{C}_{40: 10}, \mathrm{C}_{42: 11}$, and $\mathrm{C}_{44: 12}$ ) have been previously reported in phytoplankton (Hunter, 2015; Van Mooy and Fredricks, 2010). However, the most abundant DGCCs in hadal sediments have, to the best of our knowledge, not been previously reported, which highlights their potential as biomarkers of deep-sea sediments. However, three hadal stations clustered in a separate group (see Fig. S15) were dominated by DGCC$27: 0$ and did not contain DGCC-42:6, indicating that this IPL probably derives from allochthonous sources.

\subsection{Potential biological sources of other lipids}

Glycosidic ceramides (Gly-Cer) have been reported in eukaryotic algae such as prymnesiophyte (Vardi et al., 2009) and have also been shown to be abundant in water columns of OMZ systems (Schubotz et al., 2009, 2018; Cantarero et al., 2020). In general, the overlying water column shows Gly-Cer with a ceramide chain and polyunsaturated fatty acids with $\mathrm{C}_{21-38}$. However, these structures are scarce in the bathyal and hadal sediments (see Fig. S9b), which could reflect a deficient export from surface waters due to intense remineralization. On the other hand, ornithine lipids (OL), phosphatidylinositol (PI), PC-AEGs, and other unidentified phospholipids were also present in deep sediments (Fig. S9b). Some PIs and OLs have been reported in sulfate-reducing bacteria (Sturt et al., 2004; Bühring et al., 2014), whereas PC-AEGs have been reported in bacteria inhabiting water columns with reduced oxygen concentration (Schubotz et al., 2018). Thus, the high relative abundance of PC-AEG-34: 3 in hadal and bathyal sediments (Figs. S9b and S16) could be indicative of anaerobic microbial processes. PC-AEG-34:3 contributed the most to the dissimilarity between the cluster containing only hadal sediment samples (cluster 1 in Figs. 2 and 3), thus suggesting an in situ microbial production, although we cannot confidentially rule out other sources.

\subsection{Allochthonous versus autochthonous IPLs in the Atacama Trench}

Given their rapid degradation after cell death (White et al., 1979; Harvey et al., 1986; Logemann et al., 2011; Schouten et al., 2010), IPLs are typically considered markers of living or recently dead cells (White et al., 1979; Harvey et al., 1986; Petersen et al., 1991; Lipp et al., 2008). The distribution of IPLs in bathyal and hadal sediments exhibits a high degree of similitude, as demonstrated by the hierarchical analysis (cluster 1 in Fig. 8a), the NMDS (Fig. 8b), and the SIMPER analysis (cluster 1 in Table S1). The deepsea surface sediments showed weak clustering with the IPLs reported in the overlying water column by Cantarero et al. (2020) (Fig. 9a). Additionally, water-column samples exhibit a larger degree of separation than sediments (ANOSIM, $R=0.78 ; P<0.01$; Fig. $8 \mathrm{~b}$ ) and are broadly clustered by geochemical environments (Cantarero et al., 2020). The low abundance of IPLs characteristic of organisms inhabiting the chlorophyll maximum in deep-sea sediments of the Atacama Trench $(<0.005 \%$ of the total IPL pool; Fig. S3) suggests minimal export of labile organic compounds from the upper ocean. This result implies rapid IPL degradation during sinking in the water column, which is consistent with experimental degradation rates (Westrich and Berner, 1984; Logemann et al., 2011) and first-order POM sinking rates. Indeed, by using the experimentally calculated kinetic degradation rate constants $\left(k^{\prime}\right)$ of ester-bound IPLs by Logemann et al. (2011) and the sinking rate of particles from surface waters to $4000 \mathrm{~m}$ (20-100 $\mathrm{m} \mathrm{d}^{-1}$; Billett et al., 1983; Danovaro et al., 2014), we calculated that $\sim 86 \%-98 \%\left(k_{t=80}^{\prime}=0.033\right.$ and $\left.k_{t=400}^{\prime}=0.011\right)$ of IPLs from surface waters should degrade by the time that particles reach depths of $\sim 8000 \mathrm{~m}$. These results are also in accord with studies indicating elevated benthic oxygen consumption rates resulting from intense microbial respiration of sinking OM reaching the sediment (Glud et al., 2013; Wenzhöfer et al., 2016). Thus, the pool of IPLs in hadal sediments appears to predominantly represent in situ microbial production, whereas the deep-sea microbial community in both bathyal and hadal sediments is similar despite their bathymetric zonation $(\sim 1000-8000 \mathrm{~m})$. Alternatively, we cannot rule out the possibility of new IPL production, particularly from heterotrophic and chemoautotrophic bacteria in micro niches of sinking particles reaching the deep sea and/or downslope and lateral sediment transport.

Marine trenches receive organic carbon from a variety of sources and transport mechanisms. These include canyons and river systems that channel OM from land to coastal regions, aeolian transport, surface water productivity, and in situ production, to name a few (Wenzhöfer et al., 2016; Tarn et al., 2016; Luo et al., 2017; Xu et al., 2018; Guan et al., 2019; Xu et al., 2021). Carbon flux events can increase the delivery of particulate carbon from surface waters to the seafloor (Poff et al., 2021), whereas river discharge and ae- 


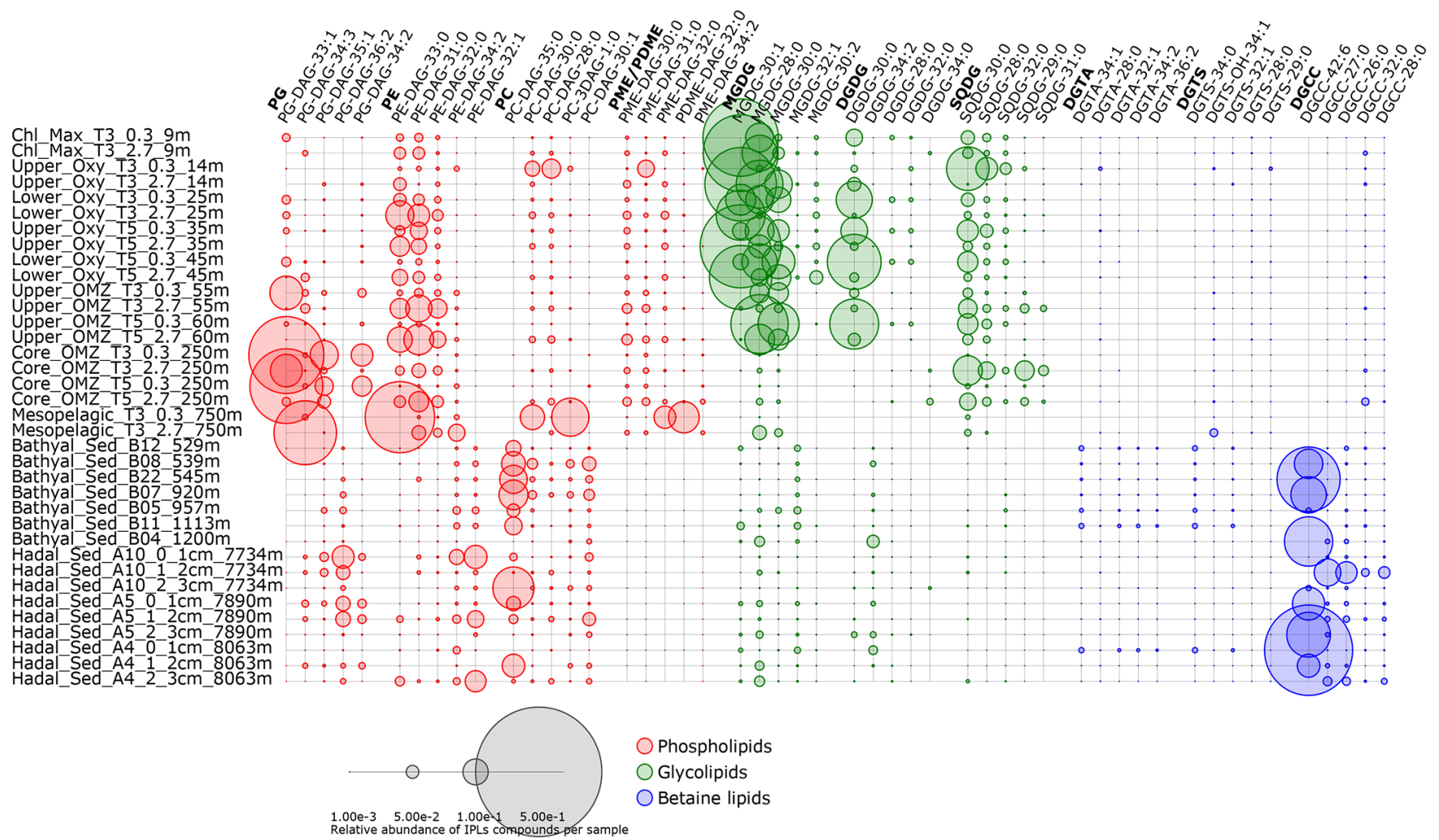

Figure 7. Relative abundance of the five most abundant individual IPLs contributing to each IPL class. Circle size is proportional to the relative abundance of IPL compounds per sample. Samples are organized along the vertical axis by depth, whereas phospholipids, glycolipids, and betaine lipids are shown in colors. The legend provides a scale for circumference size.

olian transport can result in enhanced terrestrial carbon $(\mathrm{Xu}$ et al., 2021). Mass wasting events are also known to create dynamic depositional conditions and strong spatial heterogeneity in OM distribution in marine trenches (Schauberger et al., 2021; Xu et al., 2021). While marine organic carbon appears to dominate sediments in the Japan (Schwestermann et al., 2021), Massau (Xu et al., 2020a), and New Britain (Xu et al., 2020b) trenches, the Atacama and Kermadec trenches, on the other hand, have been reported to be dominated by terrigenous OM. Since our study only focuses on the most labile component of the total lipid pool, it predominantly traces labile and indigenous $\mathrm{OM}$ and not recalcitrant fractions of the lipid pool. The latter warrants further investigation.

In regions like the Japan Trench, downslope sediment transport has been linked to earthquake-driven remobilization (Bao et al., 2018; Schwestermann et al., 2021). Whereas we lack sedimentological/geochemical data to discriminate whether the top $3 \mathrm{~cm}$ of our hadal stations represent debris flows, turbidite, or mass wasting events, ongoing work in the Atacama Trench indicates heterogenic sediment deposition along the hadal zone (Matthias Zabel, personal communication, 2021). Thus, the role of downslope transport as a mechanism to explain the high statistical similarity between bathyal and hadal sediments remains to be tested.

\subsection{Characteristic IPLs of hadal and bathyal sediments}

The IPLs that contribute most to the dissimilarity between the hierarchical cluster containing samples from the hadal and bathyal sediments (cluster 1 of Fig. 8) and the water column (cluster 2, 3, 4, and 5 of Fig. 8) are represented in Fig. 9. The most characteristic IPLs of hadal and bathyal sediments are DGCC-42:6, DGCC-27:0, DGCC-26:0, PC-DAG-35 : 0, PC-DAG-30 : 1, PC-DAG-30 : 2, PC-DAG$33: 2$, PC-DAG-32 : 1, PC-DAG-29 : 2, PE-DAG-32 : 1, PEDAG-32:2, PE-DAG-33:1, PG-DAG-36:2, and DGDG$34: 2$, which we propose as potential markers for these environments. Even though DGCCs have been mainly related to algae membranes (Kato et al., 1994; Van Mooy et al., 2009), they are minor components of the water column in this area, suggesting the occurrence of an alternative source. In addition to DGCCs, the two other betaine lipids, DGTA and DGTS, exhibited five IPLs that were almost exclusively present in sediment samples (DGTA-34:1, DGTA-32:1, DGTA-34 : 2, DGTS-34 :0, and DGTS-32: 1; see Fig. 11). We note that almost all the PC phospholipids in our study have not, to the best of our knowledge, been previously reported in the literature, which reinforces their use as markers of sedimentary in situ bathyal and hadal production. 
(a)

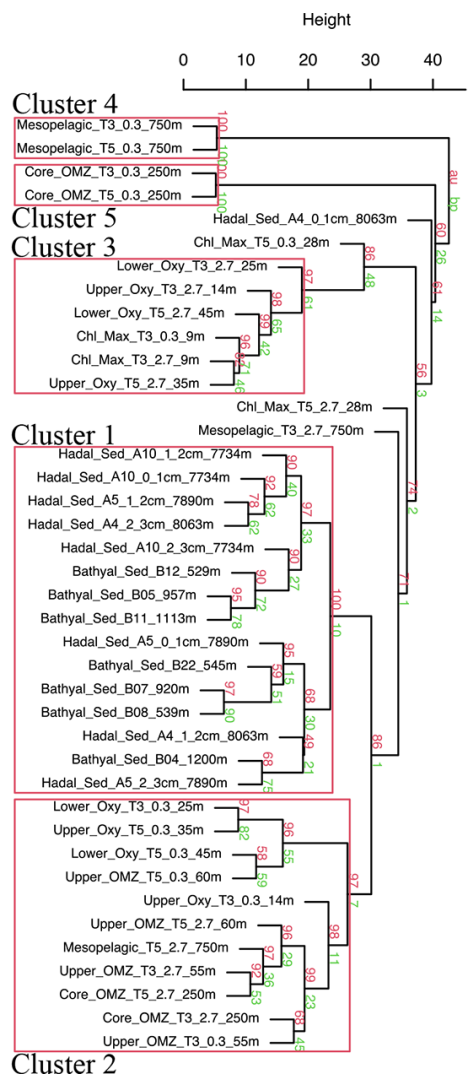

(b)

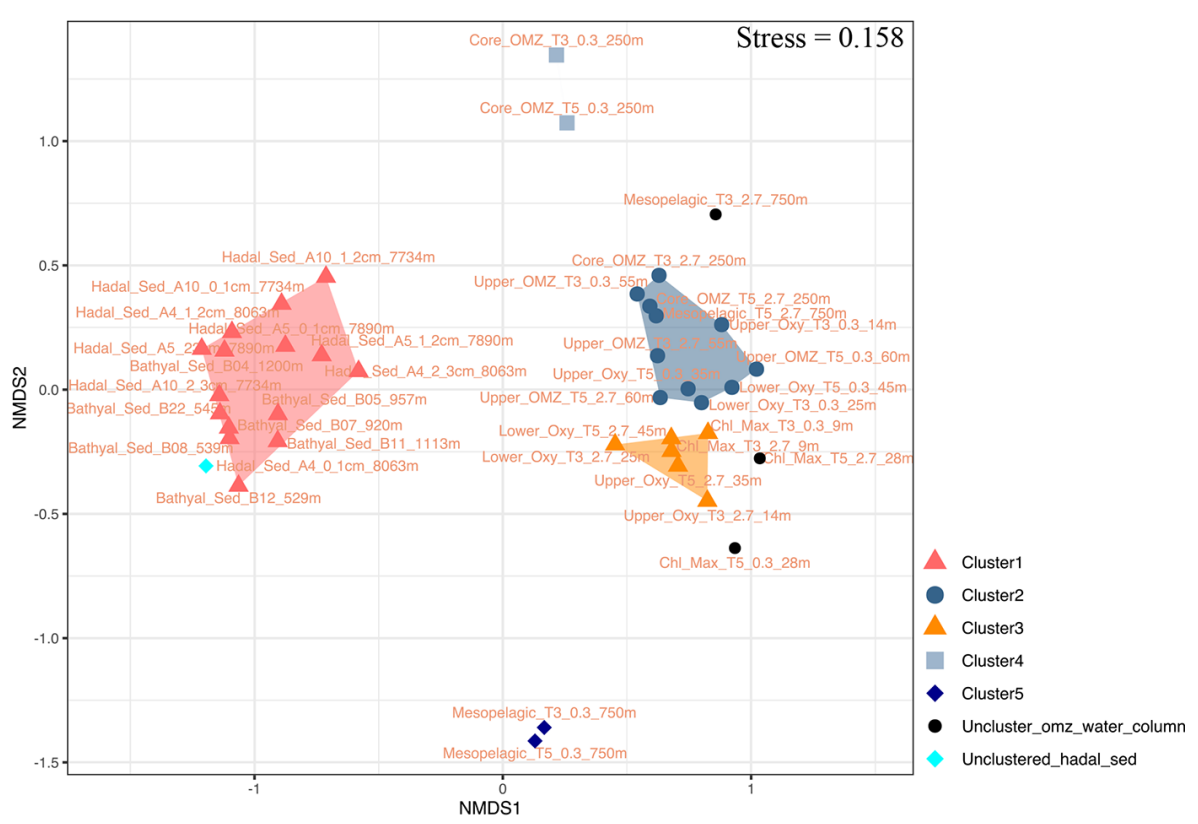

Figure 8. (a) Arithmetic mean (UPGMA) hierarchical clustering based on Euclidean distances calculated from IPLs in each sampling station. Red values are approximately unbiased (AU) $p$ values, and green values are bootstrap probability (BP) for each node. Red boxes highlight clusters with $95 \%$ confidence. The number of bootstrap replicates is 10000. (b) Non-metric multidimensional scaling (NMDS) analysis of IPLs at each sampling station. The distance matrix was calculated based on the Bray-Curtis dissimilarity. The stress value of the final configuration was $15.8 \%$. Different symbols and colors represent the sample grouping from hierarchical clusters shown in panel (a).

The presence of a few MGDGs and SQDGs in hadal and bathyal sediments ( $\sim 7 \%$ of the total IPL pool) indicates that at least some labile OM could derive from the shallow water column (see Sect. 4.2). However, the most abundant IPLs in our sediment samples, DGCC-42 : 6, PC-DAG$35: 0$, PE-DAG-32:1, and PG-DAG-36: $2(19.8 \%$ of the total IPL pool; Fig. S16), are almost completely absent in the overlying water column (Fig. 9). This reinforces the idea that these IPLs most likely originate from in situ microbial production in sediments. The single most abundant IPL in sediments, DGCC-42:6, was not present in cluster 1 , which only contains hadal sediments (Figs. 2 and 3). Instead, this compound is prominent in cluster 3,4 , and 5 , containing both hadal and bathyal samples. Thus, DGCC- $42: 6$ and PCDAG-35:0, which has the lowest relative abundance in the cluster with only hadal sediments, could be indicators of downslope transport from bathyal to hadal regions.

We acknowledge that temporal variability in IPL production in the water column and sediment and the lack of data on the largely uncharacterized hadal endemic microbial community could complicate some of the phylogenetic and source associations of IPLs and warrant further investigation. De- spite this, our study represents a step forward on the characterization of labile sources of OM sustaining hadal ecosystems.

\subsection{Do IPLs reveal homeoviscous adaptation to the deep-sea environment?}

Environmental factors such as $\mathrm{pH}$, conductivity, temperature, and pressure impact the permeability and fluidity of cell membranes (Shaw, 1974; Macdonald, 1984; DeLong and Yayanos, 1985; Somero, 1992; Komatsu and Chong, 1998; Van Mooy et al., 2009; Carini et al., 2015; Sebastián et al., 2016; Siliakus et al., 2017; Boyer et al., 2020; Allen et al., 1999). Thus, organisms adapt to changes in environmental factors to maintain physiological homeostasis by altering their fatty acid composition (DeLong and Yayanos, 1985; Fang et al., 2000; Nichols et al., 2004; Siliakus et al., 2017). For instance, the combined physiological effects of high hydrostatic pressure and low temperature on prokaryotic membranes in laboratory cultures leads to the production of unsaturated lipids (DeLong and Yayanos 1985; Fang et al., 2000; Nichols et al., 2004; Zheng et al., 2020). However, few 


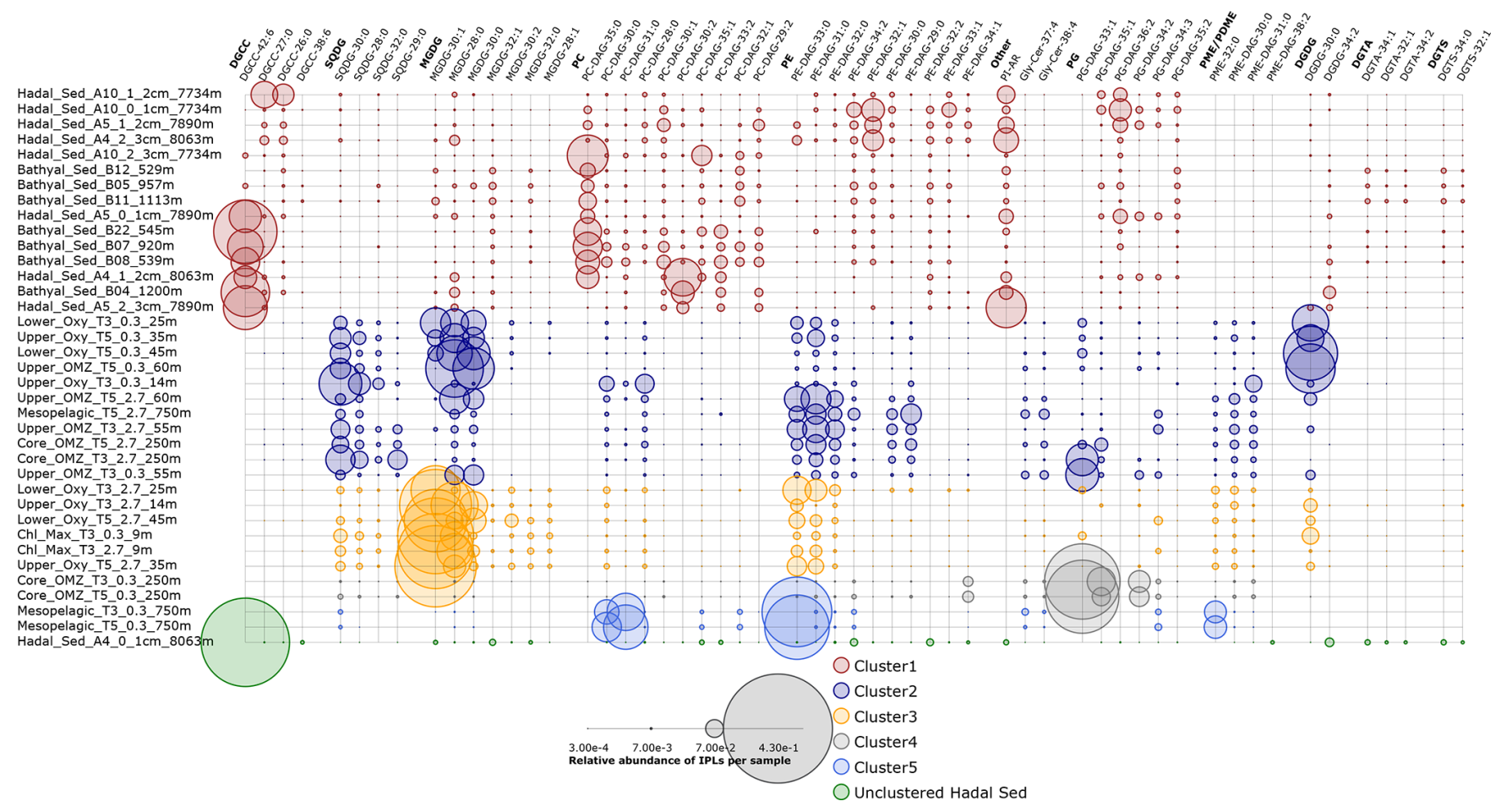

Figure 9. Relative abundance of individual IPLs that contribute most to the dissimilarity between clusters of Fig. 8 derived from the SIMPER analysis (Table S1). Circle size is proportional to the relative abundance of IPL compounds per sample. Samples are organized along the vertical axis and shown in colors that match the hierarchical cluster analysis in Fig. 8. The legend shows the scale for circumference size.

studies have been conducted using culture-independent techniques in search for potential adaptation mechanisms in organisms inhabiting the deep ocean (i.e., Zhong et al., 2020). We sought to understand whether the chemical composition of core fatty acids within different IPL classes (i.e., carbon length and unsaturation degree) reflects the combined effects of the low temperature and high pressure typical of hadal settings. We show that PGs are abundant in hadal sediments of the Atacama Trench (Fig. S4). Bacterial strains isolated from Mariana Trench sediments contain PG as the most abundant class of phospholipids (Fang et al., 2000), which these authors presumed could represent a physiological response to high pressure and low temperature. This has been confirmed by subsequent studies (Winter et al., 2009; Periasamy et al., 2009; Jebbar et al., 2015, Allemann et al., 2021). Cluster 1 in the boxplot analysis (Fig. 4) likely contains the most characteristic IPL classes of the hadal zone. In general, the phospholipids in this cluster exhibited fatty acid chains that are monounsaturated and saturated compared to other environments (Fig. 4a, b). Additionally, we observed an increase in the ratio of total unsaturated to saturated fatty acids in deep sediments compared to the water column (Fig. 5), which could reflect physiological adaptations of their biological producers. These results are in accord with studies indicating biosynthesis and incorporation of polyunsaturated fatty acids into phospholipid membranes of piezophilic bac- teria (DeLong and Yayanos, 1985; Baird et al., 1985; Yano et al., 1998; Winter, 2002; Mangelsdorf et al., 2005; Winter and Jeworrek, 2009; Allemann et al., 2021). Thus, the chemical characteristics (C length and degree of unsaturation) of the most abundant IPLs in sediments of the Atacama Trench suggest homeoviscous adaptation to this type of environment by their source organisms, in addition to potentially indicating the occurrence of compounds that are unique to the endogenous community.

\section{Conclusions}

Bacterial and eukaryotic IPLs in surface hadal sediments from the deepest points of the Atacama Trench share characteristics with those in bathyal sediments and differ from those found in suspended particles from the upper $750 \mathrm{~m}$ of the water column, including the oxygen minimum zone. This indicates that (a) most IPLs abundant in the upper water column are almost entirely degraded during their descent to the hadal seafloor and (b) IPLs found in hadal sediments are predominantly derived from in situ microbial communities.

The most dominant ester-bound IPL structures found in bathyal and hadal sediments show a great variety of phospholipids with varying degrees of unsaturation, most of them yet to be described, that are likely derived from as of yet poorly characterized bacterial and/or eukaryotes sources. Hadal sed- 
iments also exhibit unique glycolipid structures, such as SQDG-42:11, SQDG-23 : 0, DGDG-35 : 1, DGDG-35 : 2, and DGDG-37 : 1, that to the best of our knowledge have not been reported in other environments. However, these lipids are present in low abundance and represent a small fraction $(\sim 0.00012 \%)$ of the total IPL pool. Furthermore, elevated ratios of unsaturated/saturated fatty acids in hadal sediments are likely indicative of homeoviscous adaptation to the high pressure and low temperatures characteristic of this extreme deep-sea environment.

An improved understanding of the phylogenetic, ecological, and metabolic association of IPLs present in the Atacama Trench could be achieved in future studies by the pairing of lipidomics with genomic techniques (e.g., microbial community composition, functional groups, lipid biosynthesis), in addition to a detailed sedimentological and biogeochemical characterization of sediments.

Data availability. Biomarkers metadata that generates and supports the findings of this study and $\mathrm{R}$ code are available in: https://github.com/EdgartFlores/IPLs-Atacama-Trench-, last access: 3 March 2022 (https://doi.org/10.5281/zenodo.6325647, Flores, 2022).

Supplement. The supplement related to this article is available online at: https://doi.org/10.5194/bg-19-1395-2022-supplement.

Author contributions. EF, OU, and JS designed the study. MZ contributed with the hadal samples from the HADES-ERC cruise. EF prepared, extracted, and analyzed samples from the HADES-ERC cruise with help from SIC and ND under the supervision of JS. EF and SIC processed results. EF, SIC, and JS interpreted results. EF and PRF performed statistical analyses. EF wrote the manuscript with contributions from SIC, JS, and OU. All authors provided feedback on the manuscript. OU and JS funded the research.

Competing interests. The contact author has declared that neither they nor their co-authors have any competing interests.

Disclaimer. Publisher's note: Copernicus Publications remains neutral with regard to jurisdictional claims in published maps and institutional affiliations.

Acknowledgements. This work was supported by the European Research Council (HADES-ERC, grant agreement number 669947 to Ronnie N. Glud) and the Max Planck Society. Additional support was provided by the Department of Geological Sciences and INSTAAR at the University of Colorado Boulder (to Julio Sepúlveda). Edgart Flores was also partially supported by the Universidad de Concepción. We are thankful to the captains, crews, and scientists of the German RV Sonne cruises SO261 (HADES-
ERC) and SO211 (ChiMeBo). In particular, we thank the chief scientists Ronnie N. Glud and Frank Wenzhöfer (HADES-ERC) and Dierk Hebbeln (ChiMeBo). The HADES-ERC and ChiMeBo cruises were funded by the European Research Council and the German Bundesministerium für Bildung and Forschung (BMBF), respectively. We also wish to thank Carina Lange and Silvio Pantoja for access to samples from the ChiMeBo cruise and Matias Pizarro-Koch for the preparation of the three-dimensional map. We also thank Lilian Nuñez, Benjamín Srain, Rodrigo Castro, Alejandro Ávila, Mahyar Mohtadi, Ricardo De Pol-Holz, and Gema Martínez-Méndez for sample collection during the ChiMeBo cruise and/or laboratory assistance.

Financial support. This research has been supported by the Instituto Milenio de Oceanografía (grant no. ICN12_019-IMO), the Fondo Nacional de Desarrollo Científico y Tecnológico (grant no. 1191360), and the Universidad de Concepción (UCO 1866 student scholarship 2019).

Review statement. This paper was edited by Sebastian Naeher and reviewed by two anonymous referees.

\section{References}

Ahumada, R.: Producción y destino de la biomasa fitoplanctónica en un sistema de bahías en Chile central: una hipótesis, Biol. Pesq. Chile, 18, 53-66, 1989.

Allemann, M. N. and Allen, E. E.: Genetic suppression of lethal mutations in fatty acid biosynthesis mediated by a secondary lipid synthase, Appl. Environ. Microbiol., 87, e00035-21, https://doi.org/10.1128/AEM.00035-21, 2021.

Allen, E. E., Facciotti, D., and Bartlett, D. H.: Monounsaturated but not polyunsaturated fatty acids are required for growth of the deep-sea bacteriumPhotobacterium profundum SS9 at high pressure and low temperature, Appl. Environ. Microbiol., 65, 17101720, 1999.

Angel, M.: Detrital organic fluxes through pelagic ecosystems, in: Flows of energy and materials in marine ecosystems, Springer, Boston, MA, 475-516, https://doi.org/10.1007/978-14757-0387-0_19, 1984.

Angel, M. V.: Ocean trench conservation, Environmentalist, 2, 1$17,1982$.

Araki, S., Eichenberger, W., Sakurai, T., and Sato, N.: Distribution of diacylglycerylhydroxymethyltrimethyl- $\beta$-alanine (DGTA) and phosphatidylcholine in brown algae, Plant Cell Physiol., 32, 623-628, 1991.

Baird, B.: Biomass and community structure of the abyssal microbiota determined from basin and Puerto Rico trench sediments, Benthic Ecol. Sediment. Process. Venezuela Basin - Past Present, 61, 217-213, 1985.

Bao, R., Strasser, M., McNichol, A. P., Haghipour, N., McIntyre, C., Wefer, G., and Eglinton, T. I.: Tectonically-triggered sediment and carbon export to the Hadal zone, Nat. Commun., 9, 1-8, 2018.

Barridge, J. K. and Shively, J.: Phospholipids of the Thiobacilli, J. Bacteriol., 95, 2182-2185, 1968. 
Batrakov, S. G. and Nikitin, D. I.: Lipid composition of the phosphatidylcholine-producing bacterium Hyphomicrobium vulgare NP-160, Biochim. Biophys. Acta BBA-Lipids Lipid Metab., 1302, 129-137, 1996.

Benning, C., Huang, Z.-H., and Gage, D. A.: Accumulation of a novel glycolipid and a betaine lipid in cells of Rhodobacter sphaeroides grown under phosphate limitation, Arch. Biochem. Biophys., 317, 103-111, 1995.

Bergé, J.-P. and Barnathan, G.: Fatty acids from lipids of marine organisms: molecular biodiversity, roles as biomarkers, biologically active compounds, and economical aspects, Mar. Biotechnol. I, 96, 49-125, 2005.

Biddle, J. F., Lipp, J. S., Lever, M. A., Lloyd, K. G., Sørensen, K. B., Anderson, R., Fredricks, H. F., Elvert, M., Kelly, T. J., Schrag, D. P., Sogin, M. L., Brenchley, J. E., Teske, A., House, C. H., and Hinrichs, K.-U.: Heterotrophic Archaea dominate sedimentary subsurface ecosystems off Peru, P. Natl. Acad. Sci. USA, 103, 3846-3851, 2006.

Billett, D., Lampitt, R., Rice, A., and Mantoura, R.: Seasonal sedimentation of phytoplankton to the deep-sea benthos, Nature, 302, 520-522, 1983.

Bligh, E. G. and Dyer, W. J.: A rapid method of total lipid extraction and purification, Can. J. Biochem. Physiol., 37, 911-917, 1959.

Boyer, G. M., Schubotz, F., Summons, R. E., Woods, J., and Shock, E. L.: Carbon oxidation state in microbial polar lipids suggests adaptation to hot spring temperature and redox gradients, Front. Microbiol., 11, 229, https://doi.org/10.3389/fmicb.2020.00229, 2020.

Brandsma, J., Hopmans, E. C., Philippart, C. J. M., Veldhuis, M. J. W., Schouten, S., and Sinninghe Damsté, J. S.: Low temporal variation in the intact polar lipid composition of North Sea coastal marine water reveals limited chemotaxonomic value, Biogeosciences, 9, 1073-1084, https://doi.org/10.5194/bg-91073-2012, 2012.

Bühring, S. I., Kamp, A., Wörmer, L., Ho, S., and Hinrichs, K.U.: Functional structure of laminated microbial sediments from a supratidal sandy beach of the German Wadden Sea (St. PeterOrding), J. Sea Res., 85, 463-473, 2014.

Cañavate, J. P., Armada, I., and Hachero-Cruzado, I.: Interspecific variability in phosphorus-induced lipid remodelling among marine eukaryotic phytoplankton, New Phytol., 213, 700-713, 2017.

Cantarero, S. I., Henríquez-Castillo, C., Dildar, N., Vargas, C. A., Von Dassow, P., Cornejo-D’Ottone, M., and Sepúlveda, J.: Sizefractionated contribution of microbial biomass to suspended organic matter in the eastern Tropical South Pacific oxygen minimum zone, Front. Mar. Sci., 7, 745 pp., 2020.

Carini, P., Van Mooy, B. A., Thrash, J. C., White, A., Zhao, Y., Campbell, E. O., Fredricks, H. F., and Giovannoni, S. J.: SAR11 lipid renovation in response to phosphate starvation, P. Natl. Acad. Sci. USA, 112, 7767-7772, 2015.

Clarke, K. and Gorley, R.: Getting started with PRIMER v7, PrimerE Plymouth Plymouth Mar. Lab., 20, 1-18, 2015.

da Costa, E., Amaro, H. M., Melo, T., Guedes, A. C., and Domingues, M. R.: Screening for polar lipids, antioxidant, and anti-inflammatory activities of Gloeothece sp. lipid extracts pursuing new phytochemicals from cyanobacteria, J. Appl. Phycol., 32, 3015-3030, 2020.
Danovaro, R., Della Croce, N., Dell'Anno, A., and Pusceddu, A.: A depocenter of organic matter at $7800 \mathrm{~m}$ depth in the SE Pacific Ocean, Deep-Sea Res. Pt. I, 50, 1411-1420, 2003.

Danovaro, R., Snelgrove, P. V., and Tyler, P.: Challenging the paradigms of deep-sea ecology, Trends Ecol. Evol., 29, 465-475, 2014.

DeLong, E. F. and Yayanos, A. A.: Adaptation of the membrane lipids of a deep-sea bacterium to changes in hydrostatic pressure, Science, 228, 1101-1103, 1985.

Dembitsky, V. M.: Betaine ether-linked glycerolipids: chemistry and biology, Prog. Lipid Res., 35, 1-51, 1996.

Dowhan, W.: Molecular basis for membrane phospholipid diversity: why are there so many lipids?, Annu. Rev. Biochem., 66, 199232, 1997.

Eichenberger, W. and Gribi, C.: Lipids of Pavlova lutheri: cellular site and metabolic role of DGCC, Phytochemistry, 45, 15611567, 1997.

Eloe, E. A., Shulse, C. N., Fadrosh, D. W., Williamson, S. J., Allen, E. E., and Bartlett, D. H.: Compositional differences in particle-associated and free-living microbial assemblages from an extreme deep-ocean environment, Environ. Microbiol. Rep., 3, 449-458, 2011.

Fang, J., Barcelona, M. J., Nogi, Y., and Kato, C.: Biochemical implications and geochemical significance of novel phospholipids of the extremely barophilic bacteria from the Marianas Trench at 11,000 m, Deep-Sea Res. Pt. I, 47, 1173-1182, 2000.

Fernández-Urruzola, I., Ulloa, O., Glud, R., Pinkerton, M., Schneider W., Wenzhöfer, F., and Escribano, R: Plankton respiration in the Atacama Trench region: Implications for particulate organic carbon fux into the hadal realm, Limnol. Oceanogr., 66, 31343148, https://doi.org/10.1002/lno.11866, 2021.

Fischer, J. P., Ferdelman, T. G., D'Hondt, S., Røy, H., and Wenzhöfer, F.: Oxygen penetration deep into the sediment of the South Pacific gyre, Biogeosciences, 6, 1467-1478, https://doi.org/10.5194/bg-6-1467-2009, 2009.

Flores, E.: EdgartFlores/IPLs-Atacama-Trench-, v1.0.0, Zenodo [data set], https://doi.org/10.5281/zenodo.6325647, 2022.

Gao, Y., Du, X. Xu, W., Fan, R., Zhang, X., Yang, S., Chen, X., Lv, J., and Luo, Z.: Fungal diversity in deep sea sediments from east yap trench and their denitrification potential, Geomicrobiol. J., 37, 848-858, 2020.

Gašparović, B., Penezić, A., Frka, S., Kazazić, S., Lampitt, R. S., Holguin, F. O., Sudasinghe, N., and Schaub, T.: Particulate sulfur-containing lipids: Production and cycling from the epipelagic to the abyssopelagic zone, Deep-Sea Res. Pt. I, 134, 12-22, 2018.

Geiger, O., Röhrs, V., Weissenmayer, B., Finan, T. M., and ThomasOates, J. E.: The regulator gene phoB mediates phosphate stresscontrolled synthesis of the membrane lipid diacylglyceryl-N, N, N-trimethylhomoserine in Rhizobium (Sinorhizobium) meliloti, Mol. Microbiol., 32, 63-73, 1999.

Glud, R. N., Wenzhöfer, F., Middelboe, M., Oguri, K., Turnewitsch, R., Canfield, D. E., and Kitazato, H.: High rates of microbial carbon turnover in sediments in the deepest oceanic trench on Earth, Nat. Geosci., 6, 284-288, 2013.

Glud, R. N., Berg, P., Thamdrup, B., Larsen, M., Stewart, H. A., Jamieson, A. J., Glud, A., Oguri, K., Sanei, H., Rowden, A. A., and Wenzhöfer, F.: Hadal trenches are dynamic hotspots for early 
diagenesis in the deep sea, Commun. Earth Environ., 2, 1-8, 2021.

Goldfine, H.: Bacterial membranes and lipid packing theory, J. Lipid Res., 25, 1501-1507, 1984.

Goldfine, H. and Hagen, P.-O.: N-Methyl groups in bacterial lipids III. phospholipids of hyphomicrobia, J. Bacteriol., 95, 367-375, 1968.

Gombos, Z., Várkonyi, Z., Hagio, M., Iwaki, M., Kovács, L., Masamoto, K., Itoh, S., and Wada, H.: Phosphatidylglycerol requirement for the function of electron acceptor plastoquinone $\mathrm{QB}$ in the photosystem II reaction center, Biochemistry, 41, 37963802, 2002.

Gómez-Consarnau, L., González, J. M., Coll-Lladó, M., Gourdon, P., Pascher, T., Neutze, R., Pedrós-Alió, C., and Pinhassi, J.: Light stimulates growth of proteorhodopsin-containing marine Flavobacteria, Nature, 445, 210-213, 2007.

Gooday, A. J., Bett, B. J., Escobar, E., Ingole, B., Levin, L. A., Neira, C., Raman, A. V., and Sellanes, J.: Habitat heterogeneity and its influence on benthic biodiversity in oxygen minimum zones, Mar. Ecol., 31, 125-147, 2010.

Gounaris, K. and Barber, J.: Monogalactosyldiacylglycerol: the most abundant polar lipid in nature, Trends Biochem. Sci., 8, 378-381, 1983.

Gutiérrez, M. H., Vera J., Srain B., Quiñones, R. A., Wörmer L., Hinrichs K.-U., and Pantoja, S.: Biochemical fingerprints of marine fungi: implications for trophic and biogeochemical studies, Aquat. Microb. Ecol., 84, 75-90, https://doi.org/10.3354/ame01927, 2020.

Guan, H., Chen, L., Luo, M., Liu, L., Mao, S., Ge, H., Zhang, M., Fang, J., and Chen, D.: Composition and origin of lipid biomarkers in the surface sediments from the southern Challenger Deep, Mariana Trench, Geosci. Front., 10, 351-360, 2019.

Grabowski, E., Letelier, R. M., Laws, E. A., and Karl, D. M.: Coupling carbon and energy fluxes in the North Pacific Subtropical Gyre, Nat. Commun., 10, 1895, https://doi.org/10.1038/s41467019-09772-z, 2019.

Hand, K., Bartlett, D., Fryer, P., Peoples, L., Williford, K., Hofmann, A., and Cameron, J.: Discovery of novel structures at $10.7 \mathrm{~km}$ depth in the Mariana Trench may reveal chemolithoautotrophic microbial communities, Deep-Sea Res. Pt. I, 160, 103238, https://doi.org/10.1016/j.dsr.2020.103238, 2020.

Harvey, H. R., Fallon, R. D., and Patton, J. S.: The effect of organic matter and oxygen on the degradation of bacterial membrane lipids in marine sediments, Geochim. Cosmochim. Ac., 50, 795-804, 1986.

Harwood, J. L.: Membrane lipids in algae, in: Lipids in photosynthesis: structure, function and genetics, Springer, Dordrecht, 5364, https://doi.org/10.1007/0-306-48087-5_3, 1998.

Hedges, J. I., Baldock, J. A., Gélinas, Y., Lee, C., Peterson, M., and Wakeham, S. G.: Evidence for non-selective preservation of organic matter in sinking marine particles, Nature, 409, 801-804, 2001.

Heinz, E.: Enzymatic reactions in galactolipid biosynthesis, in: Lipids and lipid polymers in higher plants, Springer, Berlin, Heidelberg, 102-120, https://doi.org/10.1007/978-3-642-666322_6, 1977.

Hiraoka, S., Hirai, M., Matsui, Y., Makabe, A., Minegishi, H., Tsuda, M., Rastelli, E., Danovaro, R., Corinaldesi, C., Kitahashi, T., Tasumi, E., Nishizawa, M., Takai, K., Nomaki, H., and
Nunoura, T.: Microbial community and geochemical analyses of trans-trench sediments for understanding the roles of hadal environments, ISME J., 14, 740-756, 2020.

Houston, J.: Variability of precipitation in the Atacama Desert: its causes and hydrological impact, Int. J. Climatol. J. R. Meteorol. Soc., 26, 2181-2198, 2006.

Hunter, J. E.: Phytoplankton lipidomics: lipid dynamics in response to microalgal stressors, PhD Thesis, University of Southampton, https://ethos.bl.uk/OrderDetails.do?uin=uk.bl.ethos.675198 (last access: 3 March 2022), 2015.

Ichino, M. C., Clark, M. R., Drazen, J. C., Jamieson, A., Jones, D. O., Martin, A. P., Rowden, A. A., Shank, T. M., Yancey, P. H., and Ruhl, H. A.: The distribution of benthic biomass in hadal trenches: a modelling approach to investigate the effect of vertical and lateral organic matter transport to the seafloor, Deep-Sea Res. Pt. I, 100, 21-33, 2015.

Imhoff, J. F.: Taxonomy and physiology of phototrophic purple bacteria and green sulfur bacteria, in: Anoxygenic photosynthetic bacteria, Springer, Dordrecht, 1-15, https://doi.org/10.1007/0306-47954-0_1, 1995.

Inthorn, M., Wagner, T., Scheeder, G., and Zabel, M.: Lateral transport controls distribution, quality, and burial of organic matter along continental slopes in high-productivity areas, Geology, 34, 205-208, 2006.

Itou, M., Matsumura, I., and Noriki, S.: A large flux of particulate matter in the deep Japan Trench observed just after the 1994 Sanriku-Oki earthquake, Deep-Sea Res. Pt. I, 47, 1987-1998, 2000.

Itoh, M., Kawamura, K., Kitahashi, T., Kojima, S., Katagiri, H., and Shimanaga, M.: Bathymetric patterns of meiofaunal abundance and biomass associated with the Kuril and Ryukyu trenches, western North Pacific Ocean, Deep-Sea Res. Pt. I, 58, 86-97, 2011.

Jahnke, R. A. and Jahnke, D. B.: Rates of C, N, P and Si recycling and denitrification at the US Mid-Atlantic continental slope depocenter, Deep-Sea Res. Pt. I, 47, 1405-1428, 2000.

Jahnke, R. A., Reimers, C. E., and Craven, D. B.: Intensification of recycling of organic matter at the sea floor near ocean margins, Nature, 348, 50-54, 1990.

Jamieson, A. J., Fujii, T., Mayor, D. J., Solan, M., and Priede, I. G.: Hadal trenches: the ecology of the deepest places on Earth, Trends Ecol. Evol., 25, 190-197, 2010.

Jebbar, M., Franzetti, B., Girard, E., and Oger, P.: Microbial diversity and adaptation to high hydrostatic pressure in deep-sea hydrothermal vents prokaryotes, Extremophiles, 19, 721-740, 2015.

Kalisch, B., Dörmann, P., and Hölzl, G.: DGDG and glycolipids in plants and algae, Lipids Plant Algae Dev., 86, 51-83, 2016.

Kaneda, T.: Iso-and anteiso-fatty acids in bacteria: biosynthesis, function, and taxonomic significance, Microbiol. Mol. Biol. Rev., 55, 288-302, 1991.

Kato, C., Masui, N., and Horikoshi, K.: Properties of obligately barophilic bacteria isolated from a sample of deep-sea sediment from the Izu-Bonin trench, Oceanogr. Lit. Rev., 1, 53-54, 1997.

Kato, M., Adachi, K., Hajiro-Nakanishi, K., Ishigaki, E., Sano, H., and Miyachi, S.: betaine lipid from Pavolova lutheri, Phytochemistry, 37, 279-280, https://doi.org/10.1016/00319422(94)85041-0, 1994. 
Kioka, A., Schwestermann, T., Moernaut, J., Ikehara, K., Kanamatsu, T., Eglinton, T. I., and Strasser, M.: Event stratigraphy in a hadal oceanic trench: The Japan trench as sedimentary archive recording recurrent giant subduction zone earthquakes and their role in organic carbon export to the deep sea, Front. Earth Sci., 7, 319, https://doi.org/10.3389/feart.2019.00319, 2019.

Koblížek, M., Falkowski, P. G., and Kolber, Z. S.: Diversity and distribution of photosynthetic bacteria in the Black Sea, DeepSea Res. Pt. II, 53, 1934-1944, 2006.

Koga, Y. and Morii, H.: Biosynthesis of ether-type polar lipids in archaea and evolutionary considerations, Microbiol. Mol. Biol. Rev., 71, 97-120, 2007.

Komatsu, H. and Chong, P. L.-G.: Low permeability of liposomal membranes composed of bipolar tetraether lipids from thermoacidophilic archaebacterium Sulfolobus acidocaldarius, Biochemistry, 37, 107-115, 1998.

Lam, P., Jensen, M. M., Lavik, G., McGinnis, D. F., Müller, B., Schubert, C. J., Amann, R., Thamdrup, B., and Kuypers, M. M.: Linking crenarchaeal and bacterial nitrification to anammox in the Black Sea, P. Natl. Acad. Sci. USA, 104, 7104-7109, 2007.

Lechevalier, H.: Chemotaxonomic use of lipids-an overview, Microb. Lipids, 1, 869-902, 1988.

Leduc, D., Rowden, A. A., Glud, R. N., Wenzhöfer, F., Kitazato, H., and Clark, M. R.: Comparison between infaunal communities of the deep floor and edge of the Tonga Trench: possible effects of differences in organic matter supply, Deep-Sea Res. Pt. I, 116, 264-275, 2016.

Lipp, J. S. and Hinrichs, K.-U.: Structural diversity and fate of intact polar lipids in marine sediments, Geochim. Cosmochim. Ac., 73, 6816-6833, 2009a.

Lipp, J. S., Morono, Y., Inagaki, F., and Hinrichs, K.-U.: Significant contribution of Archaea to extant biomass in marine subsurface sediments, Nature, 454, 991-994, 2008.

Liu, J., Zheng, Y., Lin, H., Wang, X., Li, M., Liu, Y., Yu, M., Zhao, M., Pedentchouk, N., Lea-Smith, D. J., Todd, J. D., Magill, C. R., Zhang, W.-J., Zhou, S., Song, D., Zhong, H., Xin, Y., Min, Y., Tian, J., and Zhang, X.-H.: Proliferation of hydrocarbondegrading microbes at the bottom of the Mariana Trench, Microbiome, 7, 1-13, 2019.

Liu, X., Lipp, J. S., and Hinrichs, K.-U.: Distribution of intact and core GDGTs in marine sediments, Org. Geochem., 42, 368-375, 2011

Liu, X.-L., Lipp, J. S., Simpson, J. H., Lin, Y.-S., Summons, R. E., and Hinrichs, K.-U.: Mono-and dihydroxyl glycerol dibiphytanyl glycerol tetraethers in marine sediments: Identification of both core and intact polar lipid forms, Geochim. Cosmochim. Ac., 89, 102-115, 2012.

Logemann, J., Graue, J., Köster, J., Engelen, B., Rullkötter, J., and Cypionka, H.: A laboratory experiment of intact polar lipid degradation in sandy sediments, Biogeosciences, 8, 2547-2560, https://doi.org/10.5194/bg-8-2547-2011, 2011

López-Lara, I. M., Sohlenkamp, C., and Geiger, O.: Membrane lipids in plant-associated bacteria: their biosyntheses and possible functions, Mol. Plant. Microbe Interact., 16, 567-579, 2003.

Lund, E. D. and Chu, F.-L. E.: Phospholipid biosynthesis in the oyster protozoan parasite, Perkinsus marinus, Mol. Biochem. Parasitol., 121, 245-253, 2002.

Luo, M., Gieskes, J., Chen, L., Shi, X., and Chen, D.: Provenances, distribution, and accumulation of organic matter in the southern
Mariana Trench rim and slope: Implication for carbon cycle and burial in hadal trenches, Mar. Geol., 386, 98-106, 2017.

Macdonald, A.: The effects of pressure on the molecular structure and physiological functions of cell membranes, Philos. T. R. Soc. Lond. B, 304, 47-68, 1984.

Makula, R.: Phospholipid composition of methane-utilizing bacteria, J. Bacteriol., 134, 771-777, 1978.

Mangelsdorf, K., Zink, K.-G., Birrien, J.-L., and Toffin, L.: A quantitative assessment of pressure dependent adaptive changes in the membrane lipids of a piezosensitive deep sub-seafloor bacterium, Org. Geochem., 36, 1459-1479, 2005.

Martin, J. H., Knauer, G. A., Karl, D. M., and Broenkow, W. W.: VERTEX: carbon cycling in the northeast Pacific, Deep-Sea Res. Pt. I, 34, 267-285, 1987.

Matys, E., Sepúlveda, J., Pantoja, S., Lange, C., Caniupán, M., Lamy, F., and Summons, R. E.: Bacteriohopanepolyols along redox gradients in the Humboldt Current System off northern Chile, Geobiology, 15, 844-857, 2017.

Mayzaud, P., Virtue, P., and Albessard, E.: Seasonal variations in the lipid and fatty acid composition of the euphausiid Meganyctiphanes norvegica from the Ligurian Sea, Mar. Ecol. Prog. Ser., 186, 199-210, 1999.

Mirzaei, A., Rahmati, M., and Ahmadi, M.: A new method for hierarchical clustering combination, Intell. Data Anal., 12, 549-571, 2008.

Murata, N. and Siegenthaler, P.-A.: Lipids in photosynthesis: an overview, Lipids Photosynth. Struct. Funct. Genet., 6, 1-20, 1998.

Nichols, D. S., Miller, M. R., Davies, N. W., Goodchild, A., Raftery, M., and Cavicchioli, R.: Cold adaptation in the Antarctic archaeon Methanococcoides burtonii involves membrane lipid unsaturation, J. Bacteriol., 186, 8508-8515, 2004.

Nunoura, T., Takaki, Y., Hirai, M., Shimamura, S., Makabe, A., Koide, O., Kikuchi, T., Miyazaki, J., Koba, K., Yoshida, N., Sunamura, M., and Takai, K.: Hadal biosphere: insight into the microbial ecosystem in the deepest ocean on Earth, P. Natl. Acad. Sci. USA, 112, E1230-E1236, 2015.

Nunoura, T., Hirai, M., Yoshida-Takashima, Y., Nishizawa, M., Kawagucci, S., Yokokawa, T., Miyazaki, J., Koide, O., Makita, H., Takaki, Y., Sunamura, M., and Takai, K.: Distribution and niche separation of planktonic microbial communities in the water columns from the surface to the hadal waters of the Japan Trench under the Eutrophic Ocean, Front. Microbiol., 7, 1261, https://doi.org/10.3389/fmicb.2016.01261, 2016.

Nunoura, T., Nishizawa, M., Hirai, M., Shimamura, S., Harnvoravongchai P., Koide, O., Morono, Y., Fukui, T., Inagaki, F., Miyazaki, J., Takaki, Y., and Takai, K.: Microbial Diversity in Sediments from the Bottom of the Challenger Deep, the Mariana Trench, Microbes Environ., 33, 186-194, 2018.

Oksanen, J., Blanchet, F. G., Kindt, R., Legendre, P., Minchin, P., O'hara, R., Simpson, G., Solymos, P., Stevens, M., and Wagner, H.: Community ecology package, R Package Version, 2, 2013.

Oliver, J. D. and Colwell, R. R.: Extractable lipids of gram-negative marine bacteria: phospholipid composition, J. Bacteriol., 114, 897-908, 1973.

Patton, S., Lee, R. F., and Benson, A. A.: The presence of unusually high levels of lysophosphatidylethanolamine in a wax estersynthesizing copepod (Calanus plumchrus), Biochim. Biophys Acta BBA-Lipids Lipid Metab., 270, 479-488, 1972. 
Periasamy, N., Teichert, H., Weise, K., Vogel, R. F., and Winter, R.: Effects of temperature and pressure on the lateral organization of model membranes with functionally reconstituted multidrug transporter LmrA, Biochim. Biophys. Acta BBA-Biomembr., 1788, 390-401, 2009.

Petersen, S. O., Henriksen, K., Blackburn, T. H., and King, G. M.: A comparison of phospholipid and chloroform fumigation analyses for biomass in soil: potentials and limitations, FEMS Microbiol. Lett., 85, 257-267, 1991.

Pitcher, A., Villanueva, L., Hopmans, E. C., Schouten, S., Reichart, G.-J., and Sinninghe Damsté, J. S.: Niche segregation of ammonia-oxidizing archaea and anammox bacteria in the Arabian Sea oxygen minimum zone, ISME J., 5, 1896-1904, https://doi.org/10.1038/ismej.2011.60, 2011.

Poff, K. E., Leu, A. O., Eppley, J. M., Karl, D. M., and DeLong, E. F.: Microbial dynamics of elevated carbon flux in the open ocean's abyss, P. Natl. Acad. Sci. USA, 118, 4, https://doi.org/10.1073/pnas.2018269118, 2021.

Pond, D. and Harris, R.: The lipid composition of the coccolithophore Emiliania huxleyi and its possible ecophysiological significance, J. Mar. Biol. Assoc. U. K., 76, 579-594, 1996.

Popendorf, K. J., Tanaka, T., Pujo-Pay, M., Lagaria, A., Courties, C., Conan, P., Oriol, L., Sofen, L. E., Moutin, T., and Van Mooy, B. A. S.: Gradients in intact polar diacylglycerolipids across the Mediterranean Sea are related to phosphate availability, Biogeosciences, 8, 3733-3745, https://doi.org/10.5194/bg-8-37332011, 2011a.

Popendorf, K. J., Lomas, M. W., and Van Mooy, B. A.: Microbial sources of intact polar diacylglycerolipids in the Western North Atlantic Ocean, Org. Geochem., 42, 803-811, 2011 b.

Ratledge, C. and Wilkinson, S. G.: Microbial lipids, Academic press, https://doi.org/10.1002/abio.370110506, 1988.

Rex, M. A., Etter, R. J., Morris, J. S., Crouse, J., McClain, C. R., Johnson, N. A., Stuart, C. T., Deming, J. W., Thies, R., and Avery, R.: Global bathymetric patterns of standing stock and body size in the deep-sea benthos, Mar. Ecol. Prog. Ser., 317, 1-8, 2006.

Řezanka, T. and Sigler, K.: Odd-numbered very-long-chain fatty acids from the microbial, animal and plant kingdoms, Prog. Lipid Res., 48, 206-238, 2009.

Řezanka, T., Viden, I., Go, J., Dor, I., and Dembitsky, V.: Polar lipids and fatty acids of three wild cyanobacterial strains of the genus Chroococcidiopsis, Folia Microbiol., 48, 781-786, 2003.

Rossel, P. E., Elvert, M., Ramette, A., Boetius, A., and Hinrichs, K.-U.: Factors controlling the distribution of anaerobic methanotrophic communities in marine environments: evidence from intact polar membrane lipids, Geochim. Cosmochim. Ac., 75, 164184, 2011.

Rütters, H., Sass, H., Cypionka, H., and Rullkötter, J.: Monoalkylether phospholipids in the sulfate-reducing bacteria Desulfosarcina variabilis and Desulforhabdus amnigenus, Arch. Microbiol., 176, 435-442, 2001.

Sabbatini, A., Morigi, C., Negri, A., and Gooday, A. J.: Soft-shelled benthic foraminifera from a hadal site (7800 m water depth) in the Atacama Trench (SE Pacific): preliminary observations, J. Micropalaeontol., 21, 131-135, 2002.

Sakurai, I., Shen, J.-R., Leng, J., Ohashi, S., Kobayashi, M., and Wada, H.: Lipids in oxygen-evolving photosystem II complexes of cyanobacteria and higher plants, J. Biochem., 140, 201-209, 2006.
Sato, N.: Betaine lipids, Bot. Mag. Shokubutsu-Gaku-Zasshi, 105, 185-197, 1992.

Sato, N., Hagio, M., Wada, H., and Tsuzuki, M.: Requirement of phosphatidylglycerol for photosynthetic function in thylakoid membranes, P. Natl. Acad. Sci. USA, 97, 10655-10660, 2000.

Schauberger, C., Middelboe, M., Larsen, M., Peoples, L. M., Bartlett, D. H., Kirpekar, F., Rowden, A. A., Wenzhöfer, F., Thamdrup, B., and Glud, R. N.: Spatial variability of prokaryotic and viral abundances in the Kermadec and Atacama Trench regions, Limnol. Oceanogr., 66, 2095-2109, 2021.

Schneider, W., Fuenzalida, R., Garcés-Vargas, J., Bravo, L., and Lange, C.: Extensión vertical y horizontal de la zona de mínima oxígeno en el Pacífico Sur Oriental, Gayana Concepc., 70, 79$82,2006$.

Schouten, S., Middelburg, J. J., Hopmans, E. C., and Damsté, J. S. S.: Fossilization and degradation of intact polar lipids in deep subsurface sediments: a theoretical approach, Geochim. Cosmochim. Ac., 74, 3806-3814, 2010.

Schubotz, F., Wakeham, S. G., Lipp, J. S., Fredricks, H. F., and Hinrichs, K.-U.: Detection of microbial biomass by intact polar membrane lipid analysis in the water column and surface sediments of the Black Sea, Environ. Microbiol., 11, 2720-2734, 2009.

Schubotz, F., Meyer-Dombard, D., Bradley, A. S., Fredricks, H. F., Hinrichs, K.-U., Shock, E., and Summons, R. E.: Spatial and temporal variability of biomarkers and microbial diversity reveal metabolic and community flexibility in Streamer Biofilm Communities in the Lower Geyser Basin, Yellowstone National Park, Geobiology, 11, 549-569, 2013.

Schubotz, F., Xie, S., Lipp, J. S., Hinrichs, K.-U., and Wakeham, S. G.: Intact polar lipids in the water column of the eastern tropical North Pacific: abundance and structural variety of non-phosphorus lipids, Biogeosciences, 15, 6481-6501, https://doi.org/10.5194/bg-15-6481-2018, 2018.

Schwestermann, T., Eglinton, T., Haghipour, N., McNichol, A., Ikehara, K., and Strasser, M.: Event-dominated transport, provenance, and burial of organic carbon in the Japan Trench, Earth Planet. Sci. Lett., 563, 116870, https://doi.org/10.1016/j.epsl.2021.116870, 2021.

Sebastián, M., Smith, A. F., González, J. M., Fredricks, H. F., Van Mooy, B., Koblížek, M., Brandsma, J., Koster, G., Mestre, M., Mostajir, B., Pitta, P., Postle, A. D., Sánchez, P., Gasol, J. M., Scanlan, D. J., and Chen, Y.: Lipid remodelling is a widespread strategy in marine heterotrophic bacteria upon phosphorus deficiency, ISME J., 10, 968-978, 2016.

Shaw, N.: Lipid composition as a guide to the classification of bacteria, Adv. Appl. Microbiol., 17, 63-108, 1974.

Siegenthaler, P.-A.: Molecular organization of acyl lipids in photosynthetic membranes of higher plants, in: Lipids in photosynthesis: structure, function and genetics, Springer, 119-144, https://doi.org/10.1007/0-306-48087-5_7, 1998.

Siliakus, M. F., van der Oost, J., and Kengen, S. W.: Adaptations of archaeal and bacterial membranes to variations in temperature, pH and pressure, Extremophiles, 21, 651-670, 2017.

Smith, C.: Chemosynthesis in the deep-sea: life without the sun, Biogeosciences Discuss., 9, 17037-17052, https://doi.org/10.5194/bgd-9-17037-2012, 2012. 
Sohlenkamp, C., López-Lara, I. M., and Geiger, O.: Biosynthesis of phosphatidylcholine in bacteria, Prog. Lipid Res., 42, 115-162, 2003.

Somero, G. N.: Adaptations to high hydrostatic pressure, Annu. Rev. Physiol., 54, 557-577, 1992.

Stockton, W. L. and DeLaca, T. E.: Food falls in the deep sea: occurrence, quality, and significance, Deep-Sea Res. Pt. I, 29, $157-$ $169,1982$.

Sturt, H. F., Summons, R. E., Smith, K., Elvert, M., and Hinrichs, K.-U.: Intact polar membrane lipids in prokaryotes and sediments deciphered by high-performance liquid chromatography/electrospray ionization multistage mass spectrometry - new biomarkers for biogeochemistry and microbial ecology, Rapid Commun. Mass Spectrom., 18, 617-628, 2004.

Suzuki, R. and Shimodaira, H.: Pvclust: an R package for assessing the uncertainty in hierarchical clustering, Bioinformatics, 22, 1540-1542, 2006.

Ta, K., Peng, X., Xu, H., Du, M., Chen, S., Li, J., and Zhang, C.: Distributions and sources of glycerol dialkyl glycerol tetraethers in sediment cores from the Mariana subduction zone, J. Geophys. Res.-Biogeo., 124, 857-869, 2019.

Tamburini, C., Boutrif, M., Garel, M., Colwell, R. R., and Deming, J. W.: Prokaryotic responses to hydrostatic pressure in the ocean - a review, Environ. Microbiol., 15, 1262-1274, 2013.

Tarn, J., Peoples, L. M., Hardy, K., Cameron, J., and Bartlett, D. H.: Identification of free-living and particleassociated microbial communities present in hadal regions of the Mariana Trench, Front. Microbiol., 7, 665, https://doi.org/10.3389/fmicb.2016.00665, 2016.

Thompson Jr., G. A.: Lipids and membrane function in green algae, Biochim. Biophys. Acta BBA-Lipids Lipid Metab., 1302, 17-45, 1996.

Turnewitsch, R., Falahat, S., Stehlikova, J., Oguri, K., Glud, R. N., Middelboe, M., Kitazato, H., Wenzhöfer, F., Ando, K., Fujio, S., and Yanagimoto, D.: Recent sediment dynamics in hadal trenches: evidence for the influence of higher-frequency (tidal, near-inertial) fluid dynamics, Deep-Sea Res. Pt. I, 90, 125-138, 2014.

Van Mooy, B. A. and Fredricks, H. F.: Bacterial and eukaryotic intact polar lipids in the eastern subtropical South Pacific: watercolumn distribution, planktonic sources, and fatty acid composition, Geochim. Cosmochim. Ac., 74, 6499-6516, 2010.

Van Mooy, B. A., Rocap, G., Fredricks, H. F., Evans, C. T., and Devol, A. H.: Sulfolipids dramatically decrease phosphorus demand by picocyanobacteria in oligotrophic marine environments, P. Natl. Acad. Sci. USA, 103, 8607-8612, 2006.

Van Mooy, B. A., Fredricks, H. F., Pedler, B. E., Dyhrman, S. T., Karl, D. M., Koblížek, M., Lomas, M. W., Mincer, T. J., Moore, L. R., Moutin, T., Rappé, M. S., and Webb, E. A.: Phytoplankton in the ocean use non-phosphorus lipids in response to phosphorus scarcity, Nature, 458, 69-72, 2009.

Vardi, A., Van Mooy, B. A., Fredricks, H. F., Popendorf, K. J., Ossolinski, J. E., Haramaty, L., and Bidle, K. D.: Viral glycosphingolipids induce lytic infection and cell death in marine phytoplankton, Science, 326, 861-865, 2009.

Vargas, C. A., Cantarero, S. I., Sepúlveda, J., Galán, A., De PolHolz, R., Walker, B., Schneider, W., Farías, L., D’Ottone, M. C., Walker, J., Xu, X., and Salisbury, J.: A source of isotopically light organic carbon in a low-pH anoxic marine zone, Nat. Commun., $12,1-11,2021$.

Volkman, J., Jeffrey, S., Nichols, P., Rogers, G., and Garland, C.: Fatty acid and lipid composition of 10 species of microalgae used in mariculture, J. Exp. Mar. Biol. Ecol., 128, 219-240, 1989.

Wada, H. and Murata, N.: Membrane lipids in cyanobacteria, in: Lipids in photosynthesis: structure, function and genetics, Springer, 65-81, https://doi.org/10.1007/0-306-48087-5_4, 1998.

Wada, H. and Murata, N.: The essential role of phosphatidylglycerol in photosynthesis, Photosynth. Res., 92, 205-215, 2007.

Wakeham, S. G., Lee, C., Farrington, J. W., and Gagosian, R. B.: Biogeochemistry of particulate organic matter in the oceans: results from sediment trap experiments, Deep-Sea Res. Pt. I, 31, 509-528, 1984.

Wakeham, S. G., Turich, C., Schubotz, F., Podlaska, A., Li, X. N., Varela, R., Astor, Y., Saenz, J. P., Rush, D., Damste, J. S. S., Summons, R. E., Scranton, M. I. Taylor, G. T., and Hinrichs, K. -U.: Biomarkers, chemistry and microbiology show chemoautotrophy in a multilayer chemocline in the Cariaco Basin, Deep-Sea Res. Pt. I, 63, 133-156, 2012.

Warnes, G., Bolker, B., Bonebakker, L., Gentleman, R., Liaw, W., Lumley, T., Maechler, M., Magnusson, A., Moeller, S., Schwartz, M., Venables, B., and Galili, T.: gplots: various R programming tools for plotting data, R package version 2.16.0.2015, https:// github.com/talgalili/gplots (last access: 3 March 2022), 2015.

Warton, D. I., Wright, S. T., and Wang, Y.: Distance-based multivariate analyses confound location and dispersion effects, Methods Ecol. Evol., 3, 89-101, 2012.

Weijers, J. W., Schouten, S., van den Donker, J. C., Hopmans, E. C., and Damsté, J. S. S.: Environmental controls on bacterial tetraether membrane lipid distribution in soils, Geochim. Cosmochim. Ac., 71, 703-713, 2007.

Wenzhöfer, F.: The Expedition SO261 of the Research Vessel SONNE to the Atacama Trench in the Pacific Ocean in 2018 , Rep. Polar Mar. Res., 729, 1-111, 2019.

Wenzhöfer, F., Oguri, K., Middelboe, M., Turnewitsch, R., Toyofuku, T., Kitazato, H., and Glud, R. N.: Benthic carbon mineralization in hadal trenches: Assessment by in situ $\mathrm{O}_{2}$ microprofile measurements, Deep-Sea Res. Pt. I, 116, 276-286, 2016.

Wenzho"fer, F.: The Expedition SO261 of the Research Vessel SONNE to the Atacama Trench in the Pacific Ocean in 2018, Rep. Polar Mar. Res., 729, 1-111, 2019.

Westrich, J. T. and Berner, R. A.: The role of sedimentary organic matter in bacterial sulphate reduction - the G model tested, Limnol. Oceanogr., 29, 236-249, 1984.

White, D., Bobbie, R., King, J., Nickels, J., and Amoe, P.: Lipid analysis of sediments for microbial biomass and community structure, in: Methodology for biomass determinations and microbial activities in sediments, ASTM International, 673, 87103, 1979.

Winter, R.: Effect of lipid chain length, temperature, pressure and composition on the lateral organisation and phase behavior of lipid bilayer/gramicidin mixtures, Biophys. J., 1, 153A-153A, 2002.

Winter, R. and Jeworrek, C.: Effect of pressure on membranes, Soft Matter, 5, 3157-3173, 2009.

Wörmer, L., Lipp, J. S., Schröder, J. M., and Hinrichs, K.-U.: Application of two new LC-ESI-MS methods for improved detec- 
tion of intact polar lipids (IPLs) in environmental samples, Org. Geochem., 59, 10-21, 2013.

$\mathrm{Xu}$, Y., Ge, H., and Fang, J.: Biogeochemistry of hadal trenches: Recent developments and future perspectives, Deep-Sea Res. Pt. II, 155, 19-26, https://doi.org/10.1016/j.dsr2.2018.10.006, 2018.

Xu, Y., Wu, W., Xiao, W., Ge, H., Wei, Y., Yin, X., Yao, H., Lipp, S. J., Pan, B., and Hinrichs, K. U.: Intact ether lipids in trench sediments related to archaeal community and environmental conditions in the deepest ocean, J. Geophys. Res.-Biogeo., 125, e2019JG005431, https://doi.org/10.1029/2019JG005431, 2020a.

Xu, Y., Jia, Z., Xiao, W., Fang, J., Wang, Y., Luo, M., Wenzhöfer, F., Rowden, A. A., and Glud, R. N.: Glycerol dialkyl glycerol tetraethers in surface sediments from three Pacific trenches: Distribution, source and environmental implications, Org. Geochem., 147, 104079, https://doi.org/10.1016/j.orggeochem.2020.104079, 2020 b.

Xu, Y., Li, X., Luo, M., Xiao, W., Fang, J., Rashid, H., Peng, Y., Li, W., Wenzhöfer, F., Rowden, A. A., and Glud, R. N.: Distribution, Source, and Burial of Sedimentary Organic Carbon in Kermadec and Atacama Trenches, J. Geophys. Res.-Biogeo., 126, e2020JG006189, https://doi.org/10.1029/2020JG006189, 2021.
Yano, Y., Nakayama, A., Ishihara, K., and Saito, H.: Adaptive changes in membrane lipids of barophilic bacteria in response to changes in growth pressure, Appl. Environ. Microbiol., 64, 479-485, 1998.

Zheng, Y., Wang, J., Zhou, S., Zhang, Y., Liu, J., Xue, C. X., Williams, B. T., Zhao, X., Zhao, L., Zhu, X-Y., Sun, C., Zhang, H-H., Xiao, T., Yang, G-P., Todd, J. D., and Zhang, X. H.: Bacteria are important dimethylsulfoniopropionate producers in marine aphotic and high-pressure environments, Nat. Commun., 11, 1-12, https://doi.org/10.1038/s41467-020-18434-4, 2020.

Zhong, H., Lehtovirta-Morley, L., Liu, J., Zheng, Y., Lin, H., Song, D., Todd, J. D., Tian, J., and Zhang, X.-H.: Novel insights into the Thaumarchaeota in the deepest oceans: their metabolism and potential adaptation mechanisms, Microbiome, 8, 1-16, 2020.

Zhukova, N. V.: Variation in microbial biomass and community structure in sediments of Peter the Great Bay (Sea of Japan/East Sea), as estimated from fatty acid biomarkers, Ocean Sci. J., 40, 34-42, 2005 